\title{
Relationships between size-fractionated indoor and outdoor trace elements at four retirement communities in southern California
}

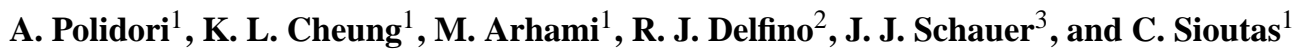 \\ ${ }^{1}$ University of Southern California, Department of Civil and Environmental Engineering, 3620 South Vermont Avenue, Los \\ Angeles, CA 90089, USA \\ ${ }^{2}$ Department of Epidemiology, School of Medicine, University of California, Irvine, Irvine, CA, 92697, USA \\ ${ }^{3}$ University of Wisconsin-Madison, Environmental Chemistry and Technology Program, 660 North Park Street, Madison, WI \\ 53706, USA
}

Received: 13 January 2009 - Published in Atmos. Chem. Phys. Discuss.: 24 February 2009

Revised: 25 June 200 - Accepted: 25 June 2009 - Published: 15 July 2009

\begin{abstract}
Indoor and outdoor water soluble trace elements (TEs) were analyzed on quasi-ultrafine (UF), accumulation, and coarse PM filter samples collected at four retirement communities, three located in the San Gabriel Valley and one in Riverside, CA. Our analysis indicates that a complex mix of vehicular, industrial, and soil-related emissions was responsible for the elemental concentrations measured at the three San Gabriel sites, while regional transport, soil re-suspension and, to a lower degree, local traffic contributed to TE levels observed in Riverside. In the quasi-UF mode, the magnitude of indoor/outdoor concentration ratios (I/O) for elements of anthropogenic origin was highly variable, reflecting the spatial heterogeneity of combustion sources in the study area. Indoor/outdoor ratios in accumulation mode PM were closer to 1 , and more homogeneous across sites, indicating that elements associated with this size fraction penetrate indoors with high efficiencies. The lowest overall I/O ratios were obtained for elements found in coarse particles, consistent with the fact that only a small portion of coarse outdoor PM infiltrates indoors. The potential of S and other TEs to serve as tracers of indoor-penetrated particles of outdoor origin was also examined. Our results suggest that using the $\mathrm{I} / \mathrm{O}$ ratio of $\mathrm{S}\left(\mathrm{I} / \mathrm{O}_{\mathrm{S}}\right)$ as a surrogate of the infiltration factor for $\mathrm{PM}_{2.5}\left[\mathrm{Finf}\left(\mathrm{PM}_{2.5}\right)\right]$ might lead to an overestimation of the indoor $\mathrm{PM}_{2.5}$ originating outdoors. This is in contrast with what was reported in previous studies conducted in the Eastern US, where $\mathrm{S}$ has been consistently used as a reliable tracer of outdoor $\mathrm{PM}_{2.5}$ infiltrating indoors. Our differences
\end{abstract}

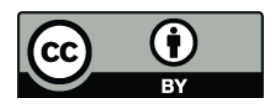

Correspondence to: C. Sioutas (sioutas@usc.edu) may be due to the fact that in the Los Angeles basin (and in general in the Western US) $\mathrm{PM}_{2.5}$ includes a number of semi-volatile labile species, such as ammonium nitrate and several organic compounds, which volatilize either entirely or to a substantial degree upon building entry.

\section{Introduction}

Numerous epidemiological and toxicological studies have found significant associations between exposure to ambient fine particulate matter $\left(\mathrm{PM}_{2.5}\right.$; aerodynamic diameter between 0.25 and $2.5 \mu \mathrm{m}$ ) and adverse respiratory and cardiovascular effects (e.g., Pope and Dockery, 2006). Correlations between adverse health effects and specific PM characteristics (particle size and number concentration, for example) and several chemical components (including trace elements; TEs) have also been reported (Burnett et al. 2000; Saldiva et al., 2002; Delfino et al., 2008). Many transition metals were designated as "hazardous air pollutants" under the 1990 US Clean Air Act Amendments, and manufacturers are required to provide emissions data for numerous metals as part of the Toxics Release Inventory. Species such as As, Cd, Co, Cr, $\mathrm{Ni}, \mathrm{Pb}$, and $\mathrm{Se}$ are human or animal carcinogens even in trace amounts (ATSDR, 2003). $\mathrm{Cu}, \mathrm{Cr}$, and $\mathrm{V}$ have been shown to generate reactive oxygen species that can contribute to oxidative DNA damage (Dreher et al., 1997; Nel, 2005).

Trace elements are emitted outdoors from both natural and anthropogenic sources (e.g. crustal material from road dust, construction activities, motor-vehicle emissions, tire/brake wear, coal and oil combustion, and incinerators). For this reason, the most abundant TEs are generally grouped into two

Published by Copernicus Publications on behalf of the European Geosciences Union. 
major groups, namely earth crust/soil-related tracers, and anthropogenic tracers. Species such as $\mathrm{Si}, \mathrm{Na}, \mathrm{Al}, \mathrm{K}, \mathrm{Mg}, \mathrm{Ca}$, $\mathrm{Fe}$, Ti and Mn comprise the majority of the Earth's crust elements, $\mathrm{S}, \mathrm{Cr}, \mathrm{Ba}, \mathrm{Mo}, \mathrm{Zn}, \mathrm{Pb}$, and $\mathrm{Cu}$ are typically released from motor-vehicle emissions and lube oil combustion, $\mathrm{Fe}$, $\mathrm{Pb}$, and $\mathrm{Zn}$ also originate from municipal waste incinerators, while $\mathrm{V}, \mathrm{Ni}$, and $\mathrm{Zn}$ are present in industrial wastes $(\mathrm{Ni}$ and $\mathrm{Zn}$ ), heating oil and bunker-fuel combustion from marine vessels ( $\mathrm{V}$ and $\mathrm{Ni}$ ). However, most of the above-mentioned TEs have multiple overlapping potential sources from industrial, transportation, combustion and other anthropogenic processes (Claiborn et al., 2002; USEPA, 2004; Thurston et al., 2005; Adgate et al., 2007). Although many studies have demonstrated that most indoor TEs in urban areas are of outdoor origin, several indoor sources may contribute substantially to indoor elemental concentrations (e.g. smoking, cooking, space heaters, and re-suspension; Weschler and Shields, 1997; Weschler, 2004). Whereas information on ambient concentrations of individual TEs associated with $\mathrm{PM}_{2.5}$ and $\mathrm{PM}_{10}$ is widely available, there is dearth of data regarding their corresponding indoor concentrations.

Because people spend $\sim 80-90 \%$ of their time indoors (Klepeis et al., 2001), and outdoor particles can enter the building envelope by convective flow (e.g., open windows) or by diffusional flow/infiltration (e.g., cracks and fissures), a significant part of their personal PM exposures occurs in indoor environments. The contribution of outdoor PM to indoor concentrations and personal exposures depends on the "infiltration factor" $\left(F_{\text {inf }}\right.$; the equilibrium fraction of outdoor PM that penetrates indoors and remains suspended; Long et al., 2001), which has typically been estimated using sulfur (S) as a marker of indoor-infiltrated particles of outdoor origin (Sarnat et al., 2002). In the absence of indoor sources of sulfur:

$F_{\text {inf }}=\mathrm{S}_{\text {in }} / \mathrm{S}_{\text {out }}$

where, $S_{\text {in }}$ and $S_{\text {out }}$ are the sulfur concentrations indoors and outdoors. However, $\mathrm{S}$ data provides only information for particles with similar penetration and deposition behavior, and reactivity (Wallace and Williams, 2005). For example, at locations where the relative contribution of semivolatile species, such as ammonium nitrate and several organic groups, to the ambient $\mathrm{PM}_{2.5}$ mass is substantial (like in the western US) the use of equation (1) might lead to an overestimation of $F_{\text {inf }}\left(\mathrm{PM}_{2.5}\right)$, because sulfur is a stable/nonvolatile compound. Trace elements other than $\mathrm{S}$ (e.g. Ni) might serve as a more accurate surrogate for outdoor infiltrated PM for some of the smaller particle size intervals and, in general, for size-fractionated PM (Long and Sarnat, 2004).

In this study, we characterized the relationships between size-fractionated indoor and outdoor concentrations of 17 water soluble TEs measured at four retirement communities of the Los Angeles basin during the Cardiovascular Health and Air Pollution Study (CHAPS), a multi-disciplinary project whose goals are to investigate the effects of microenvironmental exposures to PM on cardiovascular outcomes in elderly retirees affected by coronary artery disease. The main indoor and outdoor sources of these species and their infiltration behavior were also examined. Our results will be used by the CHAPS investigators to evaluate the relationship between human exposure to indoor and outdoor TEs from different sources and adverse health effects observed on the study subjects.

\section{Methods}

\subsection{Study design}

The physical and chemical characteristics of indoor and outdoor quasi-ultrafine (quasi-UF), accumulation, and coarse PM (here defined as particles with aerodynamic diameters less than 0.25 , between 0.25 and 2.5 , and between 2.5 and $10 \mu \mathrm{m}$, respectively) were studied at four different retirement communities of the Los Angeles basin between 2005 and 2007. Three of these communities were in the San Gabriel Valley, CA (hereafter referred to as sites San Gabriel 1, San Gabriel 2 and San Gabriel 3) and the fourth in Riverside, CA (SG1, SG2, SG3, and RIV, respectively). Site San Gabriel 1 was $\sim 50 \mathrm{Km}$ east of downtown Los Angeles, in a residential area, $\sim 3 \mathrm{Km}$ away from major freeways. Site San Gabriel 2 was $\sim 8 \mathrm{Km}$ east of Los Angeles, $\sim 300 \mathrm{~m}$ south of a major freeway, while site San Gabriel 3 was $\sim 55 \mathrm{Km}$ east of downtown Los Angeles, $\sim 2.5 \mathrm{Km}$ away from 2 busy freeways and in close proximity (less than $150 \mathrm{~m}$ ) of a major street. The Riverside site was the furthest from downtown Los Angeles $(\sim 110 \mathrm{Km}$ east) and $\sim 15 \mathrm{Km}$ southeast of downtown Riverside. The closest freeway and a major street were $\sim 3$ and 1 $\mathrm{Km}$ away, respectively, and downwind of the site.

To study the seasonal variations of indoor and outdoor size-segregated PM and its chemical components, two 6week sampling campaigns were conducted at each location. Phase 1 (hereafter referred to as P1) of each campaign was conducted during the warmer season (including summer and early fall), whereas phase 2 (P2) was conducted during the cooler season (i.e. late fall and winter). Site San Gabriel 1 was operated from 07/06/2005 to 08/20/2005 (P1) and from 10/19/2005 to 12/10/2005 (P2); sampling at site San Gabriel 2 was conducted from 08/24/2005 to $10 / 15 / 2005$ (P1) and from $01 / 04 / 2006$ to $02 / 18 / 2006$ (P2); site San Gabriel 3 was run from $07 / 05 / 2006$ to $8 / 17 / 2006$ (P1) and from 10/18/2006 to $12 / 01 / 2006$ (P2); sampling at site Riverside was carried out from 8/23/2006 to 10/13/2006 (P1) and from 01/04/2007 to $02 / 16 / 2007(\mathrm{P} 2)$.

Two identical sampling stations were installed at each site, one indoors and one outdoors. The indoor sampling station at site San Gabriel 1 was located in a recreational area of the first community's main building, adjacently to a construction site where work was ongoing. The indoor sampling area 
at site San Gabriel 2 was situated in the dining room of the community's central building, while the indoor station at site San Gabriel 3 was set up in a recreational area of the main retirement community complex, adjacent to a gym and to an activity room. The indoor sampling area at the Riverside site was located in the hallway of the main building with a dining room, activity room and numerous apartment units nearby. At all 4 sites, the outdoor station set-up inside a movable trailer was positioned within $300 \mathrm{~m}$ from the indoor station. A more detailed description of the epidemiologic study design can be found in Delfino et al., 2008.

\subsection{Sampling and chemical analyses}

Indoor and outdoor $\mathrm{CO}$ levels were measured by means of Dasibi Carbon Monoxide Analyzers (Model 3008, Dasibi Environmental Corp, Glendale, CA) in 1-min intervals. Hourly indoor and outdoor $\mathrm{PM}_{2.5}$ mass concentrations were measured using Beta-Attenuation Mass Monitors (BAM, Model 1020, Met One instruments Inc., OR), while size-segregated indoor and outdoor PM samples were collected daily from Monday to Friday by means of Sioutas ${ }^{\mathrm{TM}}$ Personal Cascade Impactors (SKC Inc, Eighty Four, PA; Misra et al., 2002; Singh et al., 2003). Coarse, accumulation, and quasi-UF mode PM were sampled on Zefluor ( $3 \mu \mathrm{m}$ pore-size, Pall Life Sciences, Ann Arbor MI) filters. The PM mass concentration was determined from the gravimetrical analysis of the Zefluor filters using a microbalance (MettlerToledo, Columbus, OH; weight uncertainty $\pm 2 \mu \mathrm{g}$ ). For more details about all integrated and continuous instruments deployed during the sampling campaign to collect/measure particle and gaseous data see Polidori et al., 2007.

Filter samples were composited weekly (including 5 daily collected samples), and analysed using Gas Chromatography/Mass Spectrometry (GC/MS) and an Inductively Coupled Plasma Mass Spectrometer (ICP-MS) to determine indoor and outdoor concentrations of 92 organic compounds and 52 trace elements, respectively (Herner et al., 2006; Stone et al., 2008). A complete characterization of the organic compounds measured indoors and outdoors can be found in Arhami et al. (2009) and it will not be discussed here.

\subsection{Data analysis}

In order to match all continuous measurements to the corresponding filter based data, only daily averages of the concurrently measured $\mathrm{PM}_{2.5}$ (BAM) and $\mathrm{CO}$ concentrations were considered. Because one of the aims of this study is to evaluate the effects of outdoor air pollutants on indoor exposure, we estimated air exchange rates (AER) from CO measurements during periods affected by a dominant indoor source (Abt et al., 2000) and determined infiltration factors $\left(F_{\text {inf }}\right)$, which are key determinants of the indoor concentrations of particulate species at times with no indoor particle sources. This was done at each of the four sites.

Assuming an exponential decay of particles, constant values for AER and outdoor concentrations during the decay period, and that indoor concentrations are well mixed, the indoor concentration of $\mathrm{CO}$ after time $t\left(C_{t}\right)$ may be expressed in the following form:

$\ln C_{t}=-(\mathrm{AER}+k) t+\ln C_{0}$

where, $t$ is the decay period considered, $C_{0}$ is the initial peak $\mathrm{CO}$ concentration (right after $\mathrm{CO}$ emission) and $k$ is the indoor loss rate for particles or gases $\left(\mathrm{h}^{-1}\right)$. Since $k$ is rather negligible for $\mathrm{CO}$, it was possible to estimate AERs directly from Eq. (2) by regressing $\ln C_{t}$ over $\ln C_{0}$.

The infiltration factor $\left(F_{\text {inf }}\right.$; Long et al., 2001) is described by the following equation:

$F_{\text {inf }}=P(\mathrm{AER}) /(\mathrm{AER}+k)$

where, $P$ is the penetration coefficient (dimensionless). It varies with particle composition, size and volatility, surface to volume ratio of the indoor sampling location and indoor air-speed. $F_{\text {inf }}$ for $\mathrm{PM}_{2.5}$ was estimated from the corresponding indoor/outdoor concentration ratios (hourly BAM measurements) at times when no indoor particle sources, such as cooking or cleaning, were likely to be present (i.e. only when I/O ratios $\leq 1$ were observed). Daily $F_{\text {inf }}$ estimates were then obtained by averaging these segregated hourly I/O ratios. Mean $F_{\text {inf }}$ for each retirement home and phase of the study were also determined by averaging the corresponding daily values.

\section{Results and discussion}

\subsection{Indoor and outdoor elemental composition}

Table 1 provides geometric means ( \pm standard deviation) of weekly averaged indoor and outdoor concentrations of selected TEs measured at the 4 retirement communities during CHAPS (i.e. $\mathrm{S}, \mathrm{Fe}, \mathrm{Na}, \mathrm{Al}, \mathrm{Mg}, \mathrm{Ba}, \mathrm{Cu}$, and $\mathrm{Zn}$ ). Data were segregated by size-fraction (quasi-UF, accumulation, and coarse PM modes), site (SG1, SG2, SG3, and RIV), and season (warmer, W, and the colder, C). All reported measurements were corrected for the corresponding field blank values and were above their detection limits. A complete summary table, including concentrations of the 17 most abundant elemental species detected during this study and discussed throughout this manuscript (i.e. $\mathrm{Na}, \mathrm{Mg}, \mathrm{Al}, \mathrm{S}, \mathrm{K}, \mathrm{Ca}, \mathrm{Ti}, \mathrm{V}, \mathrm{Cr}, \mathrm{Mn}, \mathrm{Fe}, \mathrm{Ni}, \mathrm{Cu}$, $\mathrm{Zn}, \mathrm{Mo}, \mathrm{Ba}$, and $\mathrm{Pb}$ ) is reported in the Supplemental Information (Table S1 http://www.atmos-chem-phys.net/9/4521/ 2009/acp-9-4521-2009-supplement.pdf). Most of these TEs were consistently present in both indoor and outdoor samples and, generally, the sum of their concentrations tracked 
Table 1. Geometric means ( $\mathrm{ng} / \mathrm{m}^{3} \pm$ standard deviation) of indoor (IN) and outdoor (OUT) weekly concentrations for selected trace elements at the 4 retirement communities during CHAPS. Data were segregated by site and by season (warmer, W, and the colder, C). The 3 San Gabriel Valley sites and the site in Riverside have been denoted as SG 1, SG 2, SG 3, and RIV, respectively.

\begin{tabular}{|c|c|c|c|c|c|c|c|c|c|c|c|c|c|c|c|c|c|c|c|c|c|c|c|c|c|c|c|}
\hline & & & & & $\mathrm{Na}$ & & & $\mathrm{Mg}$ & & & $\mathrm{Al}$ & & & S & & & $\mathrm{Fe}$ & & & $\mathrm{Cu}$ & & & $\mathrm{Zn}$ & & & $\mathrm{Ba}$ & \\
\hline \multirow{16}{*}{ 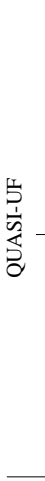 } & & \multirow{4}{*}{ W } & SG 1 & 44.1 & \pm & 1.5 & 19.1 & \pm & 2.6 & 96.6 & \pm & 2.4 & 353.3 & \pm & 1.4 & 165.0 & \pm & 3.1 & 3.53 & \pm & 1.4 & 8.69 & \pm & 1.3 & 4.41 & \pm & 1.7 \\
\hline & & & SG 2 & 30.7 & \pm & 1.6 & 17.2 & \pm & 1.5 & 74.5 & \pm & 1.9 & 353.0 & \pm & 1.2 & 61.8 & \pm & 2.6 & 3.30 & \pm & 1.5 & 5.12 & \pm & 3.8 & 2.45 & \pm & 1.9 \\
\hline & & & SG 3 & NA & \pm & NA & NA & \pm & NA & NA & \pm & NA & 204.6 & \pm & 1.5 & 7.9 & \pm & 4.3 & 0.62 & \pm & 2.5 & 2.31 & \pm & 1.3 & NA & \pm & NA \\
\hline & & & RIV & 38.2 & \pm & 2.4 & 4.9 & \pm & 2.5 & 415.6 & \pm & NA & 299.2 & \pm & 1.3 & 75.1 & \pm & 1.4 & 5.06 & \pm & 2.0 & 5.67 & \pm & 1.8 & 0.88 & \pm & 1.8 \\
\hline & & \multirow{4}{*}{$\mathrm{C}$} & SG 1 & 43.5 & \pm & 2.3 & 7.6 & \pm & 6.1 & 42.7 & \pm & 6.4 & 194.1 & \pm & 2.0 & 96.4 & \pm & 2.3 & 3.65 & \pm & 4.8 & 6.83 & \pm & 1.8 & 3.10 & \pm & 3.3 \\
\hline & & & SG 2 & 11.4 & \pm & 2.3 & NA & \pm & NA & NA & \pm & NA & 145.0 & \pm & 1.9 & 41.5 & \pm & & 3.31 & \pm & 2.5 & .02 & \pm & & 1.43 & \pm & 2.4 \\
\hline & & & SG 3 & 20.8 & \pm & 1.7 & 3.3 & \pm & 2.1 & 23.4 & \pm & 1.4 & 136.7 & \pm & 2.3 & 43.8 & \pm & 2.4 & 1.47 & \pm & 2.3 & 6.55 & \pm & 1.7 & 1.07 & \pm & 1.5 \\
\hline & & & RIV & 19.5 & \pm & 2.1 & 4.6 & \pm & 2.7 & 22.2 & \pm & 3.1 & 58.5 & \pm & 1.6 & 25.0 & \pm & 2.5 & 0.72 & \pm & 4.6 & 2.45 & \pm & 2.4 & 0.93 & \pm & 1.5 \\
\hline & \multirow{8}{*}{ OUT } & \multirow{4}{*}{ W } & SG 1 & 60.8 & \pm & 2.5 & 24.3 & \pm & 6.5 & 216.9 & \pm & 1.7 & 440.8 & \pm & 1.8 & 171.8 & \pm & 2.4 & 5.49 & \pm & 1.9 & 9.51 & \pm & 1.4 & 6.10 & \pm & 1.4 \\
\hline & & & SG 2 & 74.7 & \pm & 1.6 & 19.3 & \pm & 1.9 & 133.1 & \pm & 1.9 & 364.9 & \pm & 1.6 & 98.5 & \pm & 2.3 & 6.85 & \pm & 1.8 & 6.26 & \pm & 1.8 & 4.97 & \pm & 2.1 \\
\hline & & & SG 3 & 24.2 & \pm & 4.1 & 45.7 & \pm & NA & 64.6 & \pm & NA & 341.0 & \pm & 1.9 & 43.4 & \pm & 3.4 & 2.19 & \pm & 3.6 & 2.29 & \pm & 4.7 & 2.31 & \pm & 3.3 \\
\hline & & & RIV & 55.8 & \pm & 1.7 & 28.1 & \pm & 1.4 & 93.9 & \pm & 1.7 & 301.0 & \pm & 1.7 & 139.3 & \pm & 2.3 & 6.64 & \pm & 1.9 & 5.19 & \pm & 1.9 & 4.13 & \pm & 1.5 \\
\hline & & & SG 1 & 16.6 & \pm & 5.7 & 20.0 & \pm & 2.2 & 36.2 & \pm & 3.5 & 142.1 & \pm & 1.6 & 67.3 & \pm & 3.4 & 3.25 & \pm & 3.2 & 4.93 & \pm & 1.5 & 3.77 & \pm & 3.4 \\
\hline & & & SG 2 & 14.1 & \pm & 2.5 & 4.6 & \pm & 3.1 & 29.3 & \pm & 5.3 & 135.0 & \pm & 1.7 & 67.7 & \pm & 3.9 & 4.54 & \pm & 2.2 & 6 & \pm & 1. & 3.67 & \pm & 2.5 \\
\hline & & C & SG 3 & 44.4 & \pm & 1.3 & 13.0 & \pm & 1.4 & 65.9 & \pm & 1.1 & 154.2 & \pm & 1.5 & 106.8 & \pm & 1.3 & 5.53 & \pm & 1.6 & 8.29 & \pm & 1.3 & 3.34 & \pm & 1.6 \\
\hline & & & RIV & 27.5 & \pm & 1.2 & 12.2 & \pm & 1.7 & 46.2 & \pm & 1.9 & 52.6 & \pm & 1.5 & 63.3 & \pm & 1.3 & 2.37 & \pm & 1.3 & 3.04 & \pm & 2.1 & 1.02 & \pm & 1.5 \\
\hline & & & & & $\mathrm{Na}$ & & & $\mathrm{Mg}$ & & & $\mathrm{Al}$ & & & S & & & $\mathrm{Fe}$ & & & $\mathrm{Cu}$ & & & $\mathrm{Zn}$ & & & $\mathrm{Ba}$ & \\
\hline \multirow{16}{*}{ 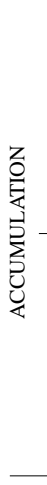 } & \multirow{8}{*}{ IN } & \multirow{4}{*}{ W } & SG 1 & 100.4 & \pm & 1.8 & 27.9 & \pm & 1.6 & 70.2 & \pm & 1.7 & 1097.3 & \pm & 1.5 & 91.8 & \pm & 1.6 & 3.36 & \pm & 1.5 & 13.84 & \pm & 1.7 & 5.86 & \pm & 1.5 \\
\hline & & & SG 2 & 152.1 & \pm & 1.7 & 26.8 & \pm & 1. & 22.5 & \pm & 1. & 503.3 & \pm & 1.8 & 91.7 & \pm & 1. & 4.99 & \pm & 1.2 & 7.02 & \pm & & 6.21 & \pm & .2 \\
\hline & & & SG 3 & 121.6 & \pm & 1.6 & 18.6 & \pm & 1.4 & 21.1 & \pm & 2.0 & 845.1 & \pm & 1.6 & 105.3 & \pm & 1.6 & 4.20 & \pm & 1.9 & 7.52 & \pm & 1.4 & 2.45 & \pm & 1.3 \\
\hline & & & RIV & 101.4 & \pm & 1.6 & 20.2 & \pm & 1.3 & 49.4 & \pm & 3.3 & 281.0 & \pm & 1.5 & 105.1 & \pm & 1.6 & 5.58 & \pm & 1.9 & 5.11 & \pm & 1.9 & 1.61 & \pm & 1.2 \\
\hline & & \multirow{4}{*}{ C } & SG 1 & 85.3 & \pm & 1.8 & 32.4 & \pm & 1.3 & 110.4 & \pm & 1.3 & 342.3 & \pm & 2.7 & 172.5 & \pm & 1.4 & 5.20 & \pm & 1.3 & 16.26 & \pm & 1.1 & 10.54 & \pm & 1.4 \\
\hline & & & SG 2 & 115.4 & \pm & 2.0 & 23.4 & \pm & 1.5 & 36.0 & \pm & 1.3 & 183.0 & \pm & 2.0 & 153.8 & \pm & 1.3 & 7.05 & \pm & 1.8 & 8.63 & \pm & 1. & 8.05 & \pm & 1.5 \\
\hline & & & SG 3 & 70.2 & \pm & 1.6 & 14.6 & \pm & 1.5 & 38.9 & \pm & 1.3 & 196.8 & \pm & 2.5 & 160.8 & \pm & 2.1 & 4.32 & \pm & 1.5 & 18.66 & \pm & 1.3 & 4.07 & \pm & 1.6 \\
\hline & & & RIV & 32.2 & \pm & 4.1 & 4.9 & \pm & 5.1 & 22.9 & \pm & 1.2 & 38.5 & \pm & 2.4 & 22.4 & \pm & 1.6 & 1.11 & \pm & 1.9 & 2.40 & \pm & 1.3 & 1.11 & \pm & 1.8 \\
\hline & & & SG 1 & 165.6 & \pm & 1.5 & 43.1 & \pm & 1.3 & 901 & \pm & 1.3 & 1397.4 & \pm & 1.3 & 162.3 & \pm & & 5.82 & & 1.4 & & & & & \pm & 1.2 \\
\hline & & & SG 2 & 290.2 & \pm & 2.1 & 54. & \pm & 1.4 & 88.7 & \pm & 1. & 799.6 & \pm & 1. & 0 & \pm & & 8.94 & \pm & & & \pm & & 3.73 & \pm & 1.5 \\
\hline & & W & SG 3 & 385.3 & \pm & 1.7 & 58.2 & \pm & 1.6 & 61.6 & \pm & 1. & 1182.2 & \pm & 2. & 5 & \pm & & 4.35 & \pm & 1. & 5 & \pm & & 7.44 & \pm & 1.3 \\
\hline & & & RIV & 158.9 & \pm & 1.2 & 37.7 & \pm & 1.2 & 127.0 & \pm & 1.7 & 492.2 & \pm & 1.5 & 135.4 & \pm & 1.5 & 4.02 & \pm & 2.0 & 6.83 & \pm & 1.5 & 3.78 & \pm & 1.5 \\
\hline & & & SG 1 & 67.4 & \pm & 1.7 & 28.7 & \pm & 1.5 & 78.6 & \pm & 1.7 & 309.7 & \pm & 2.5 & 178.7 & \pm & 1.4 & 5.35 & \pm & 1.5 & 12.50 & \pm & 1.3 & 13.38 & \pm & 1.3 \\
\hline & & & SG 2 & 204.8 & \pm & 1.8 & 38.8 & \pm & 1.5 & 71.1 & \pm & 1.7 & 332.4 & \pm & 2.3 & 241.4 & \pm & 1.3 & 10.80 & \pm & 1.3 & 3.19 & \pm & 1.3 & 15.23 & \pm & 1.4 \\
\hline & & $\mathrm{C}$ & SG 3 & 85.0 & \pm & 1.5 & 23.3 & \pm & 1.3 & 58.1 & \pm & 1.4 & 283.3 & \pm & 2.4 & 123.5 & \pm & 1.3 & 4.43 & \pm & 1.2 & 13.12 & \pm & 1.4 & 7.92 & \pm & 1.3 \\
\hline & & & RIV & 47.3 & \pm & 2.5 & 13.6 & \pm & 2.0 & 39.6 & \pm & 1.9 & 72.1 & \pm & 2.3 & 56.0 & \pm & 1.5 & 1.91 & \pm & 1.4 & 4.65 & \pm & 1.8 & 2.77 & \pm & 1.7 \\
\hline & & & & & $\mathrm{Na}$ & & & $\mathrm{Mg}$ & & & $\mathrm{Al}$ & & & S & & & $\mathrm{Fe}$ & & & $\mathrm{Cu}$ & & & $\mathrm{Zn}$ & & & $\mathrm{Ba}$ & \\
\hline & & & SG 1 & 61.7 & \pm & 1.6 & 25.2 & \pm & 1.6 & 77.6 & \pm & & & \pm & & & & & 1.6 & & & & & & 28 & \pm & 1.8 \\
\hline & & & SG 2 & 56.4 & \pm & 2.0 & 14.7 & \pm & 1.5 & 21.0 & \pm & 1.5 & 14.0 & \pm & 1.7 & 39.5 & \pm & 1. & 3.30 & \pm & 4.0 & 5.0 & \pm & 4.0 & 1.85 & \pm & 1.3 \\
\hline & & W & SG 3 & 7.3 & \pm & 2.0 & 1.9 & \pm & 1.1 & 5.8 & \pm & 3.4 & 3.5 & \pm & 2.2 & 11.1 & \pm & 1. & 0.97 & \pm & 1.8 & 0.3 & \pm & 15.6 & 0.26 & \pm & 1.9 \\
\hline & & & RIV & 33.5 & \pm & 2.0 & 10.3 & \pm & 2.3 & 33.3 & \pm & 2.7 & 13.4 & \pm & 1.7 & 49.1 & \pm & 1.8 & 1.74 & \pm & 1.3 & 1.37 & \pm & 4.0 & 0.97 & \pm & 1.8 \\
\hline & & & SG 1 & 84.3 & \pm & 1.8 & 40.0 & \pm & 1.3 & 131.1 & \pm & 1.4 & 53.5 & \pm & 1.8 & 131.3 & \pm & 1.3 & 3.10 & \pm & 2.1 & 68 & \pm & 2.2 & 6.25 & \pm & 1.4 \\
\hline & & & SG 2 & 23.2 & \pm & 2. & 9.8 & \pm & 1.8 & 9.5 & \pm & 4. & 6.7 & \pm & 2. & 39. & \pm & 1 & 3.1 & \pm & & 2. & \pm & & 1.9 & \pm & 1.8 \\
\hline & & $\mathrm{C}$ & SG 3 & 17.2 & \pm & 2.7 & 6.5 & \pm & 2.1 & 19.2 & \pm & 2.3 & 12.7 & \pm & 1.7 & 30.0 & \pm & 2. & 1.82 & \pm & 2.3 & 1.7 & \pm & & 1.23 & \pm & 2.0 \\
\hline$\stackrel{\overrightarrow{2}}{\stackrel{4}{4}}$ & & & RIV & 29.5 & \pm & 2.3 & 16.0 & \pm & 1.3 & 53.4 & \pm & 1.1 & 11.4 & \pm & 1.3 & 35.2 & \pm & 1.2 & 0.76 & \pm & 1.2 & 1.98 & \pm & 1.3 & 1.00 & \pm & 1.2 \\
\hline & & & SG 1 & 71.0 & \pm & 1.3 & 120.7 & \pm & 1.3 & 366.6 & \pm & 1. & & \pm & 1. & & \pm & & & \pm & 1.2 & & \pm & & 18.79 & \pm & 1.2 \\
\hline & & & SG 2 & 497.1 & \pm & 1.9 & 95.2 & \pm & 1.4 & 184.6 & \pm & 1.2 & 123.5 & \pm & 1. & 329.3 & \pm & 1. & 12.96 & \pm & 1.4 & 9.6 & \pm & 1. & 22.52 & \pm & 1.4 \\
\hline & & W & SG 3 & 423.8 & \pm & 1.6 & 98.3 & \pm & 1.3 & 195.3 & \pm & 1.4 & 105.0 & \pm & 1.5 & 256.3 & \pm & 1. & 7.75 & \pm & 1.3 & 4.7 & \pm & 1. & 14.13 & \pm & 1.3 \\
\hline & & & RIV & 219.4 & \pm & 1.2 & 108.0 & \pm & 1.4 & 418.0 & \pm & 1.5 & 75.7 & \pm & 2.0 & 408.3 & \pm & 1.5 & 5.25 & \pm & 1.5 & 3.61 & \pm & 1.5 & 9.32 & \pm & 1.6 \\
\hline & OUT & & SG 1 & 112.0 & \pm & 2.2 & 45.7 & \pm & 1.3 & 124.4 & \pm & 1.4 & & \pm & 1. & & \pm & 1. & 7.4 & \pm & 1.9 & & + & 2. & & \pm & 1.4 \\
\hline & & & SG 2 & 246.5 & \pm & 1.7 & 60.7 & \pm & 1. & 148.2 & \pm & 1. & 58.5 & \pm & 1. & 290.5 & \pm & 1. & 12.91 & \pm & 1.7 & 9.0 & \pm & 2. & 20.23 & \pm & 1.5 \\
\hline & & C & SG 3 & 188.3 & \pm & 1.7 & 79.3 & \pm & 1.5 & 188.4 & \pm & 1.8 & 52.3 & \pm & 1.4 & 252.4 & \pm & 1.7 & 8.37 & \pm & 1.4 & 4.85 & \pm & 1. & 14.65 & \pm & 1.6 \\
\hline & & & RIV & 86.9 & \pm & 1.9 & 39.1 & \pm & 1.4 & 131.1 & \pm & 1.7 & 21.8 & \pm & 2.0 & 108.2 & \pm & 1.6 & 2.23 & \pm & 1.3 & 2.10 & \pm & 1.5 & 3.57 & \pm & 1.6 \\
\hline
\end{tabular}

the corresponding PM level well within each size-fraction (Table S2).

At all sites and during the course of the study, elemental indoor and outdoor concentrations in all size-fractions were clearly divided in 2 groups based on their concentration. The most abundant species included $\mathrm{Al}, \mathrm{S}, \mathrm{K}, \mathrm{Ca}, \mathrm{Fe}$, and $\mathrm{Na}$ (75-441, 65-1397, and 121-497 ng/m 3 , for quasi-UF, accumulation, and coarse mode $\mathrm{PM}$, respectively), while $\mathrm{Mg}$, Ti, $\mathrm{V}, \mathrm{Cr}, \mathrm{Mn}, \mathrm{Ni}, \mathrm{Cu}, \mathrm{Zn}, \mathrm{Mo}, \mathrm{Ba}$, and $\mathrm{Pb}$, were measured in concentrations from 2 to $46 \mathrm{ng} / \mathrm{m}^{3}$ (quasi-UF), 1 to $58 \mathrm{ng} / \mathrm{m}^{3}$ (accumulation), and 1 to $23 \mathrm{ng} / \mathrm{m}^{3}$ (coarse). Representative examples of these "high" and "low" levels groups are shown in Fig. 1. Sulfur was the element with the highest indoor and outdoor concentrations in the quasi-UF and accumulation modes (especially in the warmer months), followed by $\mathrm{Fe}, \mathrm{Na}, \mathrm{Al}$, and other soil-related species (Fig. 1a). Unusually high indoor measurements of $\mathrm{Al}$ were obtained in the quasi-UF PM collected in Riverside; the reason for the elevated indoor levels remains unclear, but it is likely that this species may have unknown indoor sources.

At all sites, the outdoor concentrations of elements in the accumulation mode (as well as those in quasi-UF and coarse 

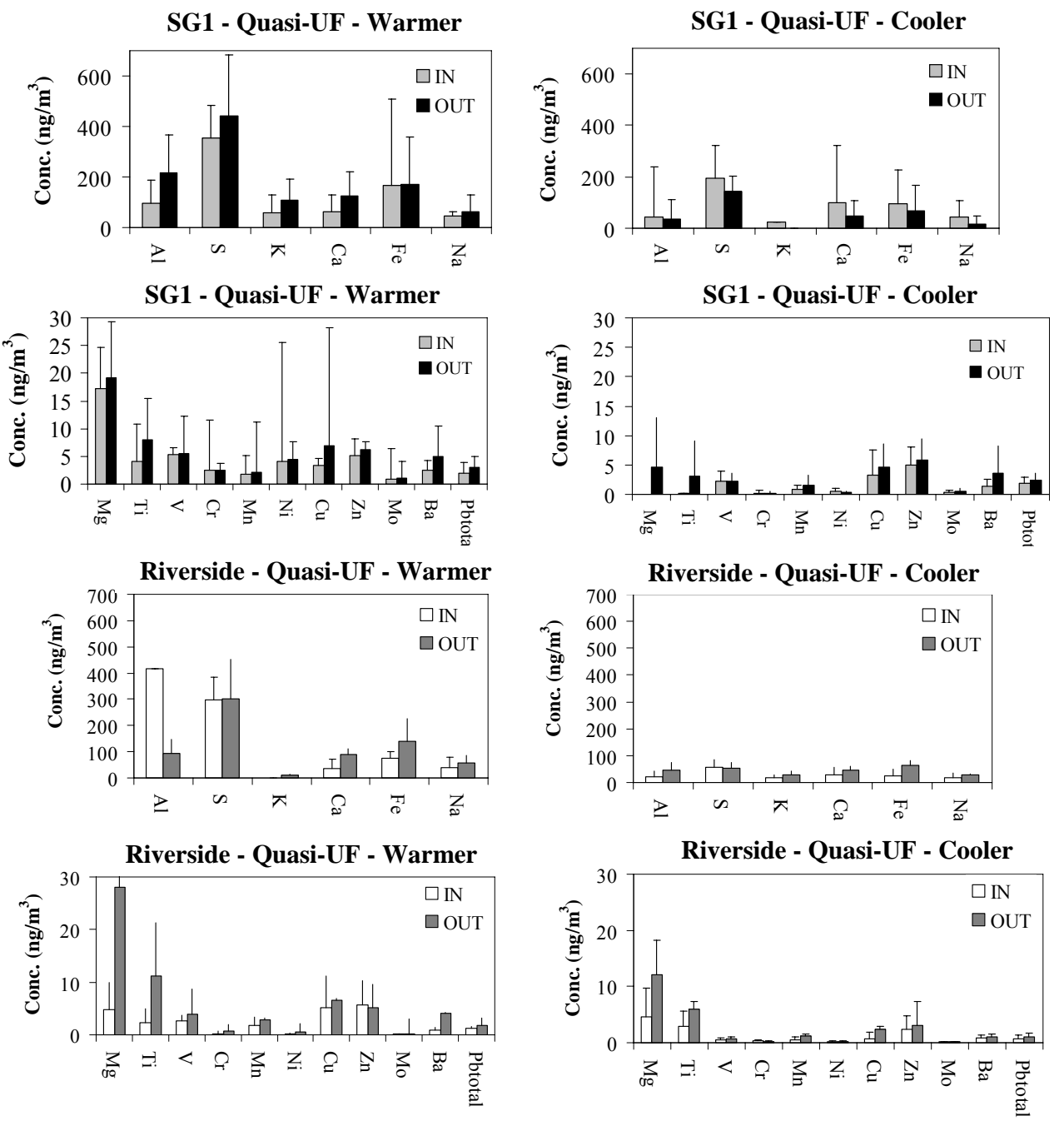

Fig. 1a. Geometric mean indoor (IN) and outdoor (OUT) concentrations of the 17 most abundant trace elements detected at one of the San Gabriel valley retirement communities (SG1) and in Riverside (RIV) in quasi-UF (a), accumulation (b) and coarse (c) mode particles. Data were reported for both the warmer and the cooler months (summer-early fall and late fall-winter, respectively). Vertical bars represent standard deviations for each element $( \pm \mathrm{SD})$.

mode PM) was higher in the warmer periods than in the cooler months (Fig. 1b), which is reflective of advection and local transport of TEs emitted mostly in the source areas of western and central Los Angeles, located upwind of the study sites. $\mathrm{Al}, \mathrm{Fe}$, and $\mathrm{Na}$ were the most important elemental components of coarse PM (Fig. 1c). Indoor and outdoor elemental concentrations were typically lower during the cooler months compared to the warmer periods, probably because of lower wind speeds and wetter soil conditions, which tend to limit re-suspension of TEs associated with this size fraction.

Correlations among outdoor elemental concentrations are consistent with the influence of three major outdoor source types for these TEs: motor vehicle/combustion emissions, resuspended soil dust, and regional transport. For example, at all retirement communities, outdoor quasi-UF S, Cr, Ba, Mo, $\mathrm{Zn}, \mathrm{Pb}$ and $\mathrm{Cu}$ were well correlated with each other (Spearman correlation coefficient, or R, ranged from 0.60 to 0.95 ; $p<0.05$ ), suggesting a common origin, probably from vehicular sources and lube oil combustion. In Riverside, outdoor quasi-UF $\mathrm{V}$ and $\mathrm{Ni}$ showed moderately strong associations $(\mathrm{R}=0.69 ; p<0.05)$, confirming the presence of fuel oil combustion emissions in this area.

Outdoor $\mathrm{S}$ in the accumulation mode was significantly $(p<0.05)$ correlated with $\mathrm{Na}, \mathrm{Mg}, \mathrm{V}$, and $\mathrm{Pb}$ at the $\mathrm{San}$ Gabriel sites, and $\mathrm{Na}, \mathrm{Mg}, \mathrm{Al}, \mathrm{V}, \mathrm{Cr}, \mathrm{Mn}, \mathrm{Fe}, \mathrm{Ni}, \mathrm{Cu}$, and Mo in Riverside, which suggests that most of these elements originate from a mix of mobile, industrial and other anthropogenic combustion sources. In addition, outdoor $\mathrm{S}$ was highly correlated with $\mathrm{Ni}$, especially in Riverside ( $\mathrm{R}=0.91$; 

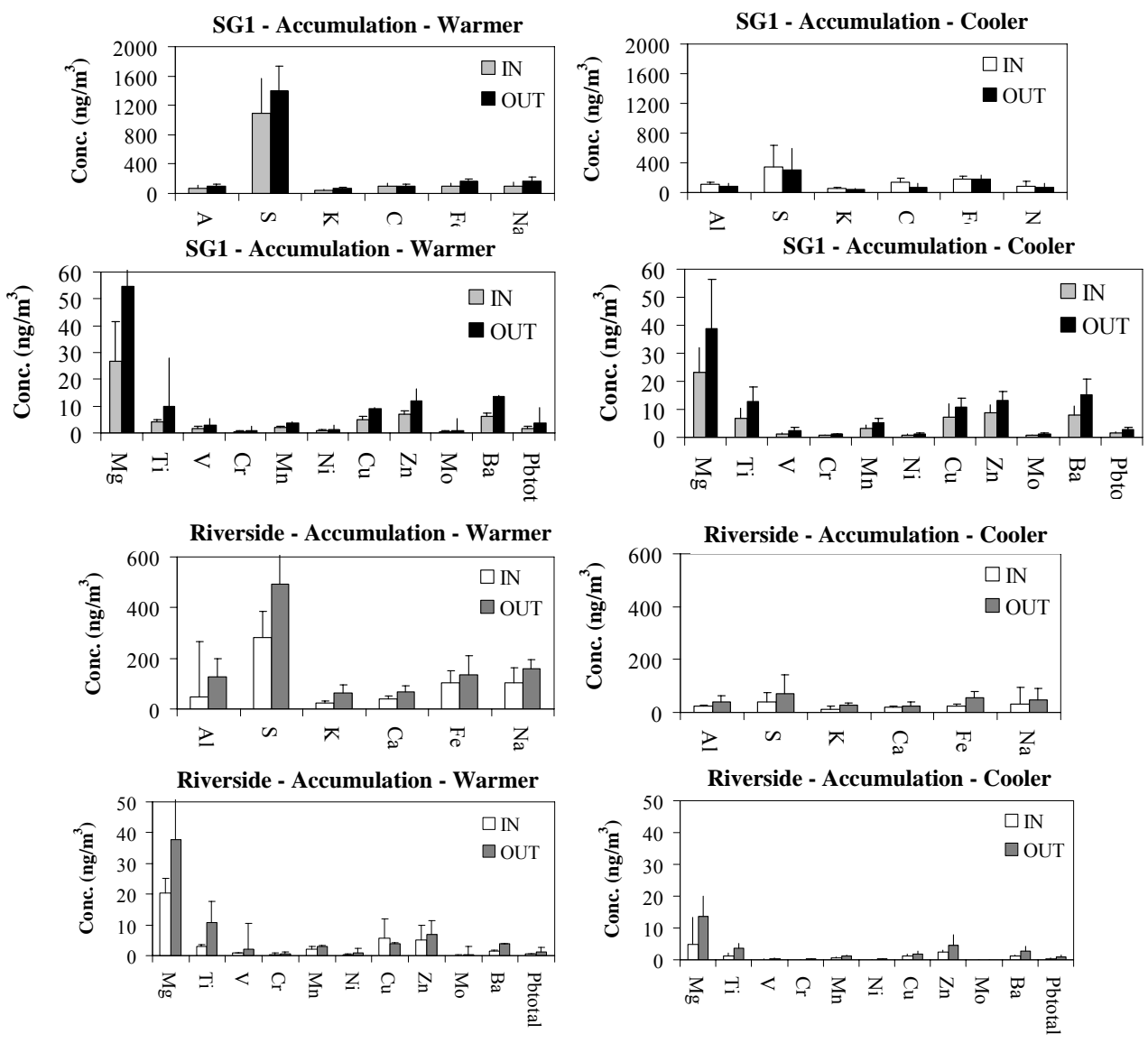

Fig. 1b. Continued.

$p<0.0001$ ); this is consistent with regional transport of fossil fuel combustion as a source of both of these elements (Long and Sarnat, 2004). According to Sardar et al. (2005), Riverside is a typical "receptor" site of pollutants emitted from the Los Angeles area.

Consistent with our expectations, outdoor species in coarse mode PM associated with re-suspended soil dust such as $\mathrm{K}, \mathrm{Mg}, \mathrm{Al}, \mathrm{Ca}, \mathrm{Ti}, \mathrm{Fe}$ and $\mathrm{Mn}$ were highly correlated with each other both at the San Gabriel sites and in Riverside, with Spearman correlation coefficients ranging from $\sim 0.7$ to $0.99(p \ll 0.05)$. Moreover, statistically significant correlations ( $\sim 0.40$ to $0.85 ; p<0.05$ ) were observed at all locations among outdoor $\mathrm{Ni}, \mathrm{Zn}$ and $\mathrm{Fe}$ (three elements with potential industrial sources), especially in the coarse mode. An analysis of the correspondent outdoor-indoor Spearman correlations coefficients showed that most of the TEs found indoors were of outdoor origin. Additional details about the influence of outdoor sources on measured indoor TEs concentrations are reported in the following sections.

\subsection{Indoor/outdoor elemental ratios}

Figure 2 shows median indoor/outdoor concentration ratios (I/O) for TEs measured at the combined San Gabriel valley sites (SG) and in Riverside (RIV) both in the warmer and in the cooler seasons. Regression slopes (S) and Spearman correlation coefficients (R) for the corresponding indoor/outdoor correlations are also reported. In the quasi-UF mode (Fig. 2a), the magnitude of $\mathrm{I} / \mathrm{O}, \mathrm{S}$ and $\mathrm{R}$ values for TEs of both crustal and anthropogenic origin was highly variable. This likely reflects the spatial heterogeneity of combustion sources, such as motor vehicle emissions, the relatively short atmospheric residence time of this size fraction, and the fact that changes in home characteristics, such as surface/volume ratio, air exchange rates, and ventilation conditions might have different effects on indoor elemental concentrations at different retirement communities. The I/O ratio of $\mathrm{Cr}$ in Riverside (cooler season) was particularly high (2.32), suggesting the presence of a potential indoor source (e.g. Cr is present as a pigment in paints and paint sprays; http://oehha.ca.gov).

Indoor/outdoor ratios, $\mathrm{S}$, and $\mathrm{R}$ data in accumulation mode PM were more homogeneous across sites and their 

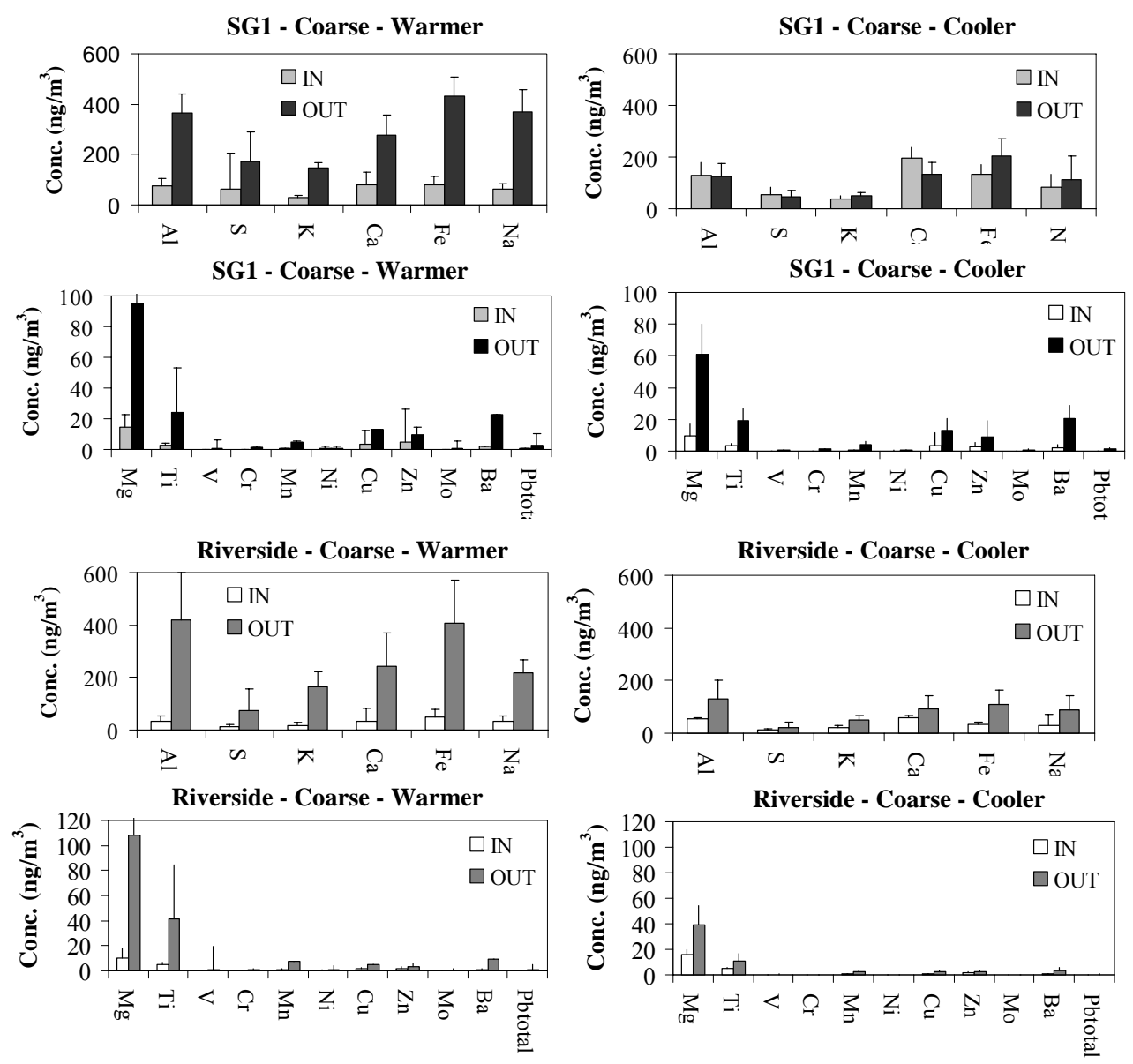

Fig. 1c. Continued.

magnitude showed a lower variability among TEs (Fig. 2b). As expected, most I/O values were closer to 1 , indicating that elements associated with particles in this size fraction penetrate indoors with relatively high efficiencies and remain suspended. Slope and $\mathrm{R}$ values were also higher than those observed in Fig. 2a, especially for TEs of anthropogenic origin, confirming that a significant fraction of their indoor concentrations can be attributed to infiltration of outdoor particles. Similar results have been observed in several other studies conducted both in the United States (Geller et al., 2002; Long and Sarnat, 2004; Adgate et al., 2007) and around the world (Chao et al., 2002; Janssen et al., 2005; Wang et al., 2006). In the warmer months, comparable I/O data for most elements were observed at the San Gabriel valley and the Riverside sites, while ratios were somewhat smaller in Riverside during the cooler periods. This suggests that at this site, the relative contribution of crustal elements to the total measured outdoor TEs concentration was higher from mid fall to late winter, because soil-related material does not penetrate indoors very efficiently.

The I/O ratios of $\mathrm{Cu}$ in Riverside (warmer season) and of $\mathrm{Zn}$ at the San Gabriel valley sites (cooler season) were

slightly higher than $1\left[\mathrm{I} / \mathrm{O}_{\mathrm{Cu}}\right.$ (Riverside) $=1.35 ; \mathrm{I} / \mathrm{O}_{\mathrm{Zn}}$ (San Gabriel $)=1.15$ ], indicating the presence of a potential indoor source of these 2 elements (Fig. 2b). This is somewhat puzzling because $\mathrm{Zn}$ (typically found in particles smaller than $0.5 \mu \mathrm{m}$ ) is mostly emitted from anthropogenic sources such as fossil fuel combustion, although it has also been found in cigarette smoke (Jones et al., 2000). Although always statistically significant $(p \ll 0.05)$, $\mathrm{R}$ values associated with TEs in accumulation mode particles are generally lower than those reported in other publications (Long and Sarnat, 2004; Janssen et al. 2005, Adgate et al. 2007), probably because the AERs at the four retirement communities were relatively low (average AERs varied from 0.25 to $0.40 \mathrm{~h}^{-1}$ in the warmer seasons and from 0.26 to $0.33 \mathrm{~h}^{-1}$ in the colder seasons; Table 2). The low AERs estimated in this study are consistent with the structural characteristics of the sampling locations (two recreational areas, a dining room, and a hallway; all well insulated environments), the low number of open windows and doors, and the presence of central air conditioners (Polidori et al., 2007).

The lowest overall I/O ratios and $\mathrm{S}$ data were obtained for coarse mode particles (Fig. 2c), which is consistent with the 
Quasi-UF - Warmer Season
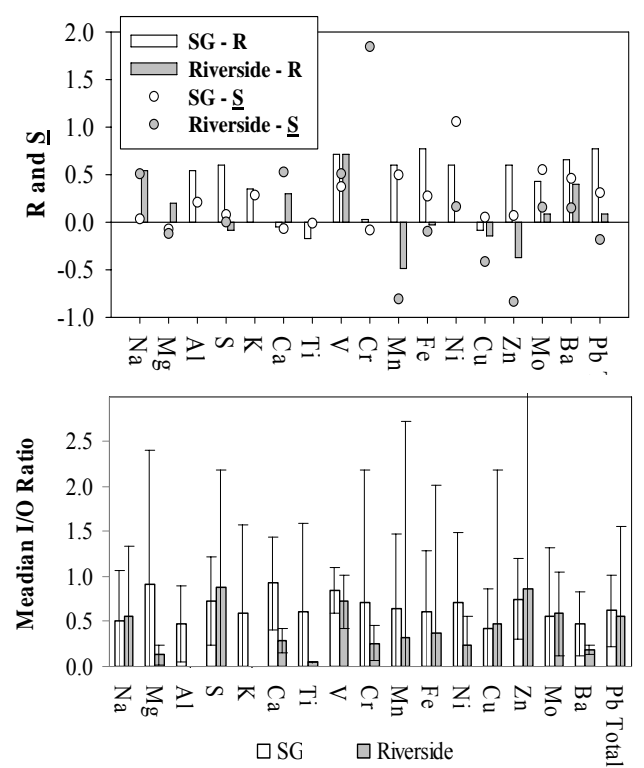

Quasi-UF - Cooler Season
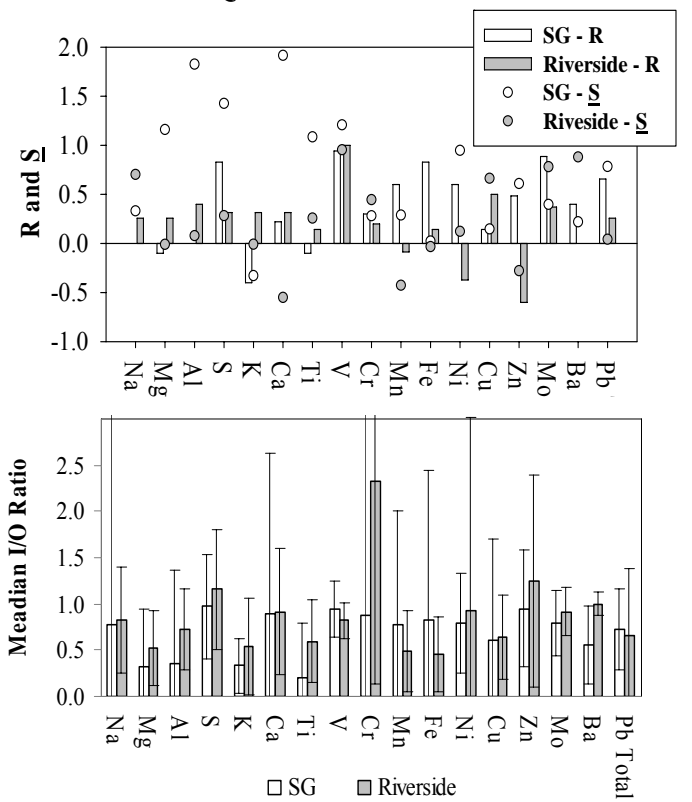

Fig. 2a. Median indoor/outdoor concentration ratios (I/O) of the 17 most abundant trace elements measured at the San Gabriel valley sites (SG) and in Riverside (RIV) in quasi-UF (a), accumulation (b) and coarse (c) mode particles. I/O, regression slopes (S), and Spearman correlation coefficients (R) data are reported for both the warmer and the cooler months (summer-early fall and late fall-winter, respectively). Vertical bars represent standard deviations for each element $( \pm \mathrm{SD})$.
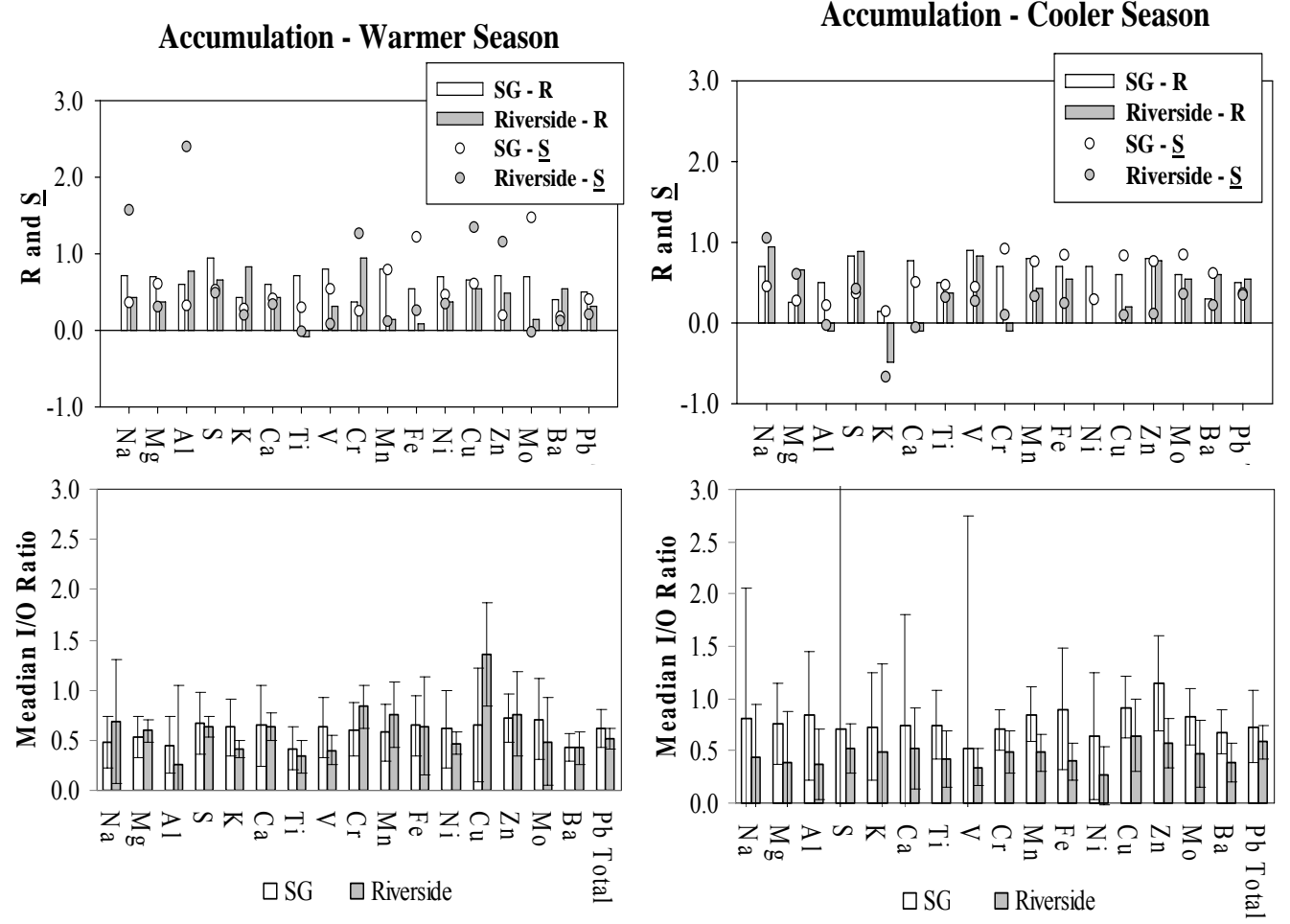

Fig. 2b. Continued. 

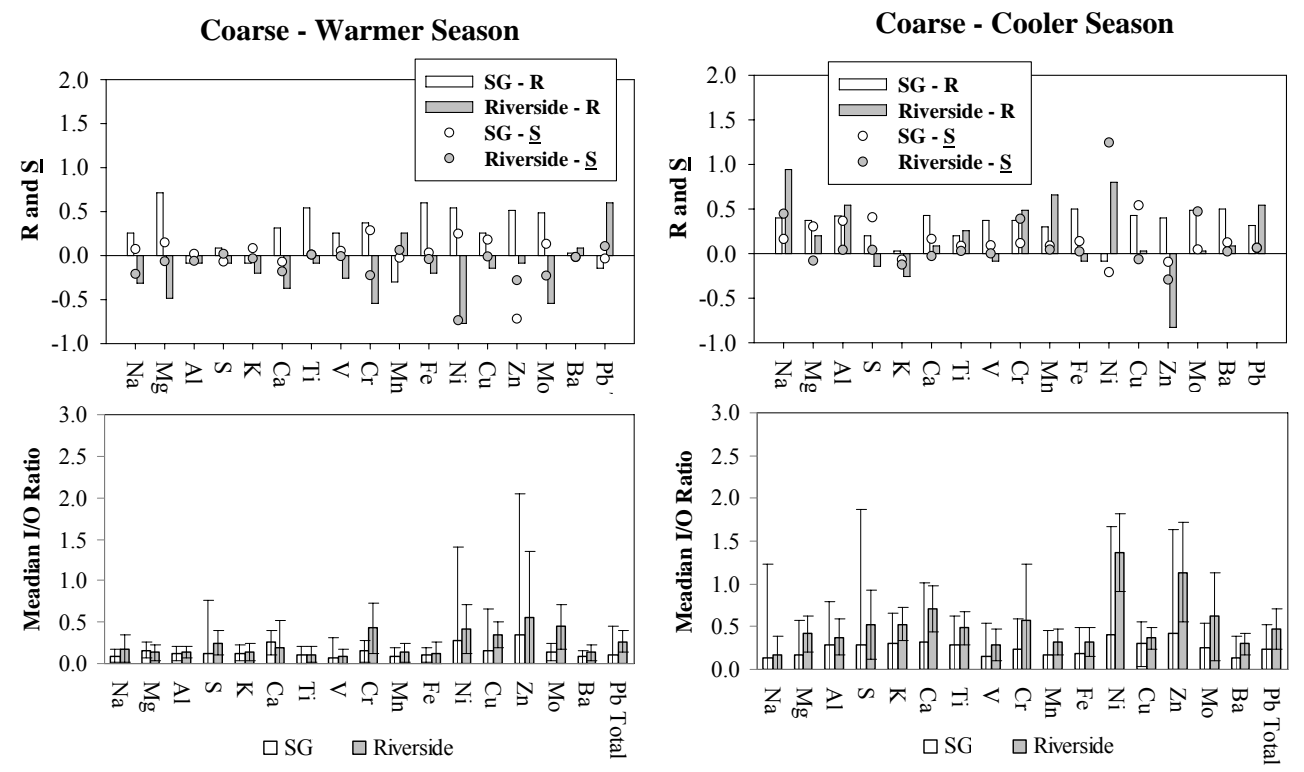

Fig. 2c. Continued.

Table 2. Air Exchange Rates (AERs) Infiltration factors for fine PM (Finf( $\left.\mathrm{PM}_{2.5}\right)$ ) estimates at the four retirement homes during CHAPS. AERs were determined using CO measurements during periods affected by a dominant indoor source, while Finf $\left(\mathrm{PM}_{2.5}\right)$ were calculated from indoor/outdoor BAM data at times when no indoor PM sources were present (i.e. (indoor $\mathrm{PM}_{2.5} /$ outdoor $\mathrm{PM}_{2.5}$ ) $\leq 1$ ).

\begin{tabular}{llllll}
\hline & & \multicolumn{2}{c}{ AER, $\mathrm{h}^{-1}$} & \multicolumn{1}{c}{$F_{\text {inf }}$} \\
\hline & & \multicolumn{2}{c}{$($ mean $\pm S D)$} & $\mathrm{PM}_{2.5}$ \\
\hline & San Gabriel 1 & 0.25 & \pm & 0.04 & 0.52 \\
Phase 1 (summer and fall) & San Gabriel 2 & 0.28 & \pm & 0.06 & 0.45 \\
& San Gabriel 3 & 0.40 & \pm & 0.12 & 0.42 \\
& Riverside & 0.21 & \pm & 0.06 & 0.49 \\
\hline \multirow{3}{*}{ Phase 2 (fall and winter) } & San Gabriel 1 & 0.33 & \pm & 0.07 & 0.52 \\
& San Gabriel 2 & 0.31 & \pm & 0.10 & 0.38 \\
& San Gabriel 3 & 0.26 & \pm & 0.08 & 0.57 \\
& Riverside & 0.31 & \pm & 0.09 & 0.41 \\
\hline
\end{tabular}

fact that only a small fraction of coarse outdoor particles infiltrates indoors. Coarse PM, mostly from soil-related material, has also high deposition velocities, which contribute to lowering the $\mathrm{I} / \mathrm{O}$ ratio of elements bound to this particle size range (Abt et al., 2000). During the warmer seasons, I/O values for all reported TEs were $0.08-0.35$ at the San Gabriel sites [average I/O (San Gabriel) $=0.15 \pm 0.08$ ] and $0.09-0.56$ in Riverside [average I/O (Riverside) $=0.24 \pm 0.15$ ], while slightly higher values were observed in the cooler periods, probably because of increased indoor activities related to the higher amount of time spent indoors in that period. The low $\mathrm{R}$ values ( $<0.4$ for most TEs) associated with this size fraction are probably due to differences in the building tightness and indoor ventilation conditions, and to the variable influence of indoor sources across the four sampling sites. Cleaning, dusting, washing, vacuuming, and other indoor activities have been shown to affect indoor coarse PM concentrations through particle generation and re-suspension (Weschler and Shields, 1997; Weschler, 2004). The I/O ratios of $\mathrm{Ni}$ and $\mathrm{Zn}$ in Riverside during the cooler season were relatively high $\left(\mathrm{I} / \mathrm{O}_{\mathrm{Ni}}=1.36 ; \mathrm{I} / \mathrm{O}_{\mathrm{Zn}}=1.13\right.$; Fig. $\left.2 \mathrm{c}\right)$, indicating the presence of a potential indoor emission of these 2 elements. The major source of indoor exposure to $\mathrm{Ni}$ and $\mathrm{Zn}$ is tobacco smoke (unlikely, in our case), wood smoke, suspended soil particles, and cooking (for Zn only). Studies have shown that indoor concentrations of coarse particlebound $\mathrm{Ni}$ often exceed outdoor concentrations in several California homes (http://oehha.ca.gov). 


\subsection{Emission factors and source contributions}

Figure 3 shows indoor and outdoor size-fractionated Upper Continental Crust (UCC) enrichment factors (EFs) (Ntziachristos et al., 2007) for the 17 most abundant TEs measured at the four retirement communities during the warmer and the cooler seasons. The concentration of each element was normalized to $\mathrm{Al}$ and then divided by the relative abundance of the same species over $\mathrm{Al}$ in UCC (Arhami et al., 2008).

$\mathrm{EF}=(\mathrm{X} / \mathrm{Al})_{\mathrm{air}} /(\mathrm{X} / \mathrm{Al})_{\mathrm{UCC}}$

where, $(\mathrm{X} / \mathrm{Al})_{\text {air }}$ and $(\mathrm{X} / \mathrm{Al})_{\mathrm{UCC}}$ are concentration ratios between element $\mathrm{X}$ and $\mathrm{Al}$ in the air and in the UCC, respectively. For each individual element, values close to 1 suggest a crustal origin, while much higher EFs indicate emission from an anthropogenic source.

In each size fraction, the grey region represents the area including the average EFs calculated at the three San Gabriel valley sites (SG), while the solid triangles correspond to average EFs in Riverside (RIV). Indoor and outdoor emission factors for most of the selected TEs were higher in the quasiUF and accumulation modes (Fig. 3a and b, respectively) compared to the coarse mode (Fig. 3c), as $\mathrm{PM}_{2.5}$ (quasiUF+accumulation particles) mostly originates from anthropogenic sources.

The lowest coarse mode EFs were observed for $\mathrm{Na}, \mathrm{Al}, \mathrm{Ca}$, $\mathrm{Ti}, \mathrm{Mn}, \mathrm{Fe}$, and $\mathrm{K}$, indicating that these airborne species are likely to be products of sea salt and re-suspended soil dust. Higher $\mathrm{EFs}$ for $\mathrm{S}, \mathrm{V}, \mathrm{Cr}, \mathrm{Ni}, \mathrm{Cu}, \mathrm{Zn}, \mathrm{Mo}, \mathrm{Ba}$, and $\mathrm{Pb}$ were found in all size fractions, especially in the quasi-UF and accumulation modes, indicating that the majority of these elements are probably emitted from vehicular sources and lube oil combustion (Chao et al., 2002; Wang et al., 2006; Ntziachristos et al., 2007). Specifically, S (which exists mostly as sulfate) is an oxidation product of sulfur dioxide and is formed almost exclusively outdoors, $\mathrm{Cu}$ and $\mathrm{Ba}$ originate from vehicle brake abrasion (Sanders et al., 2003; Sternbeck et al., 2002), $\mathrm{Zn}$ is mostly a product of tire attrition (Singh et al., 2003), $\mathrm{V}$ and $\mathrm{Ni}$ are present in fuel oil and natural gas combustion emissions (especially in Southern California), $\mathrm{Pb}$ is attributed to wheel weights and gasoline exhaust (Sternbeck et al., 2002), while Ni, $\mathrm{Zn}$ and Fe are considered to be good tracers of industrial sources (Long and Sarnat, 2004). These results are consistent with those reported in other studies conducted both in the Los Angeles area (Ntziachristos et al., 2007; Arhami et al., 2008) and in other urban locations (Chao et al., 2002; Wang et al., 2006; Lin et al., 2005; Birmili et al., 2006). The vanadium-to-nickel ratio (V/Ni) can be used to distinguish between different emission sources. In particular, ratios higher than 1.5 suggest that these two TEs originate from fuel oil combustion, values around 1 indicate the influence of industrial sources, and smaller ratios indicate diesel and gasoline engine emissions (Isakson et al., 2001; Lin et al., 2005). During CHAPS, outdoor and indoor
$\mathrm{V} / \mathrm{Ni}$ ratios in fine (quasi-UF + accumulation) mode particles tracked each other well and were always higher than 1.5 (values ranged from 1.69 to 10.51 at the San Gabriel valley sites and from 3.40 to 6.85 in Riverside), highlighting the importance of fuel oil combustion emissions from vehicular and industrial sources.

The indoor and outdoor EF profiles in each size fraction were very similar both at the San Gabriel valley sites and in Riverside, suggesting that at all retirement communities the PM composition was influenced by a similar natu$\mathrm{ral} /$ anthropogenic source mix. However, the magnitude of these profiles were slightly lower in Riverside than at the San Gabriel valley homes (in all size fractions), suggesting a higher relative contribution of TEs of crustal origin at that site. This is a reasonable outcome, because the retirement community in Riverside is the furthest from downtown Los Angeles ( $\sim 110 \mathrm{Km}$ east), it is located in a non-densely populated/remote area, surrounded by a desert, where the influence of anthropogenic sources (e.g. motor-vehicle emissions) is not as important as at the three San Gabriel valley communities. Variations in the average indoor and outdoor EFs for all TEs across the three San Gabriel valley sites were the lowest for quasi-UF and accumulation mode particles and highest for coarse mode PM, as indicated by the size of the corresponding grey areas in Fig. 3a, b, and c, respectively. This is consistent with the higher spatial variability of coarse particles, whose concentrations decrease rapidly away from the emission source because of their relatively low residence time and increased deposition velocity. By comparison, accumulation mode PM is influenced by contributions from both local emissions and aged particles transported from upwind regions. Hence their outdoor concentrations are typically less variable within the same study area (e.g. the San Gabriel valley).

\subsection{Elements as tracers of size-fractionated/indoor- infiltrated outdoor PM}

As pointed out by Long and Sarnat (2004), in order for a PM component to serve as an accurate tracer of ambient particles in indoor environments, this species must: (a) be present in sufficient quantities both indoors and outdoors, (b) preserve its chemical characteristics after infiltrating the building envelope, (c) be characterized by insignificant indoor source contributions, and (d) have similar penetration, deposition, and chemical properties as other outdoor PM constituents. Elemental species such as $\mathrm{Ni}, \mathrm{Zn}, \mathrm{Fe}$ and especially $\mathrm{S}$, have been used or proposed as tracers of indoor infiltrated particles emitted / formed outdoors (Sarnat et al., 2002; Long and Sarnat 2004; Wallace and Williams, 2005). However, the infiltration behavior of a "non-conservative" species such as PM might not be properly captured using conservative tracers, especially at locations where the contribution of volatile and semi-volatile components (e.g. ammonium nitrate and 

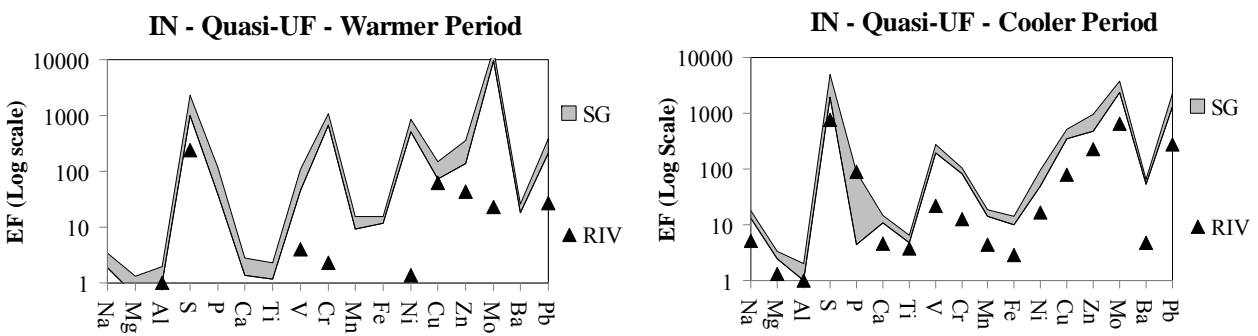

\section{OUT - Quasi-UF - Warmer Period}
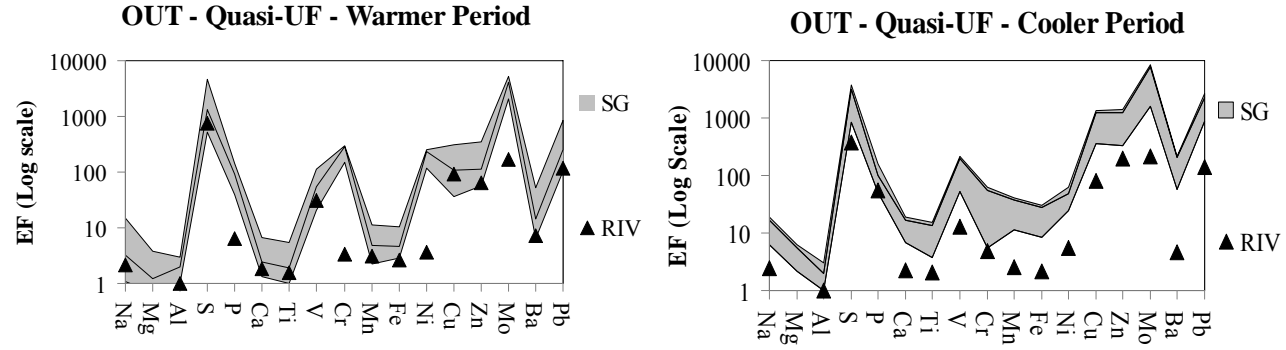

Fig. 3a. Indoor (IN) and outdoor (OUT) Upper Continental Crust (UCC) enrichment factors (EFs) for the 17 most abundant trace elements detected at San Gabriel valley sites (SG; range is indicated by the grey area) and in Riverside (RIV; solid triangles) in quasi-UF (a), accumulation (b) and coarse (c) mode particles. EF data are reported for both the warmer and the cooler months (summer-early fall and late fall-winter, respectively).
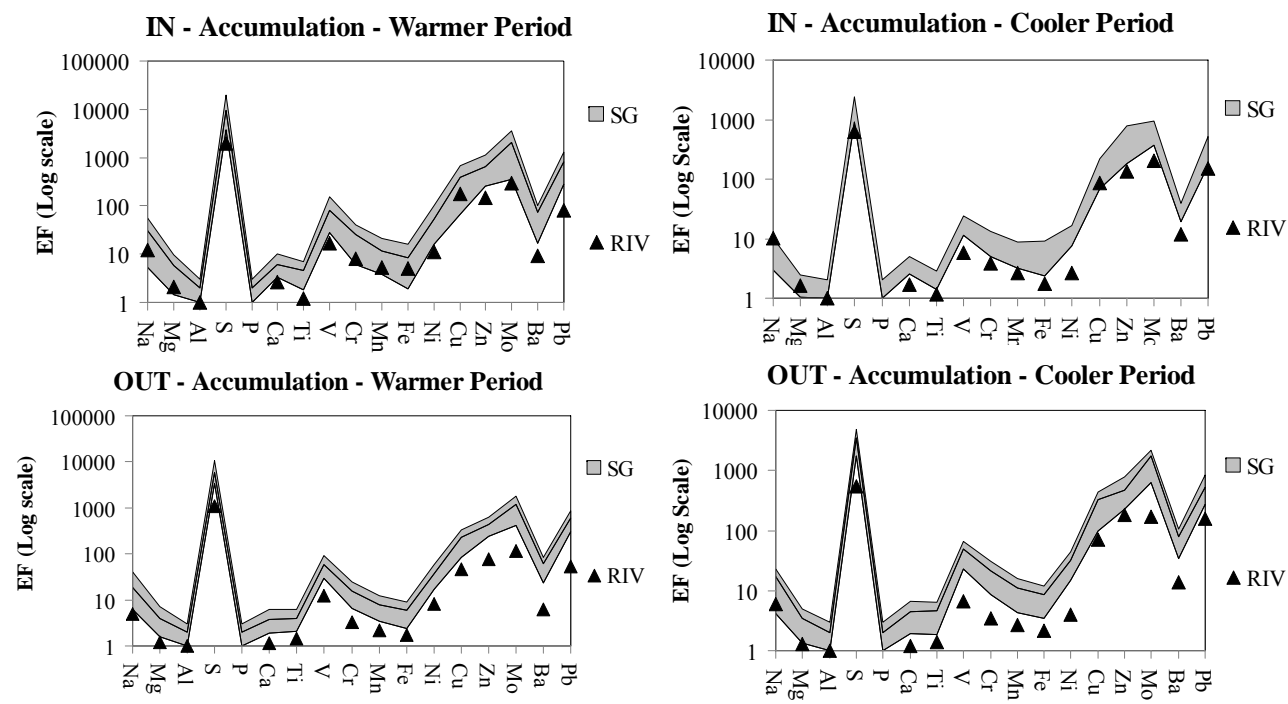

Fig. 3b. Continued.

several organic species) to the measured outdoor PM mass is substantial.

In this work, we analyzed the elemental infiltration behavior of $\mathrm{S}, \mathrm{Ni}, \mathrm{Zn}$, and $\mathrm{Fe}$, and their potential to serve as tracers of indoor-infiltrated quasi-UF, accumulation, and coarse particles of outdoor origin. These four elements (with typical mass median diameters of about $0.5-1.0 \mu \mathrm{m}$ for $\mathrm{S}, \mathrm{Ni}$, $\mathrm{Zn}$, and 3-4 $\mu \mathrm{m}$ for Fe, respectively; Milford and Davidson, 1985), were consistently detected in both indoor and outdoor samples at all four retirement homes, are known to be conservative (Koutrakis et al. 1992), and have no significant in- door sources (Jones et al., 2000). Following a methodology that uses regression analysis and graphical displays (Sarnat et al., 2002; Long and Sarnat, 2004) we assessed the ability of the $\mathrm{I} / \mathrm{O}$ ratios of $\mathrm{S}, \mathrm{Ni}, \mathrm{Zn}$, and $\mathrm{Fe}$ to estimate corresponding I/O ratios of quasi-UF, accumulation, and coarse mode PM (Fig. 4). Because a conventional linear least-squares regression assumes that there are uncertainties only in the dependent variable, a Deming linear least-squares regression was used instead, and the uncertainties in $\mathrm{I} / \mathrm{O}_{\mathrm{PM} \text { fraction }}$ and $\mathrm{I} / \mathrm{O}_{\mathrm{TE}}$ were considered in the calculations. 

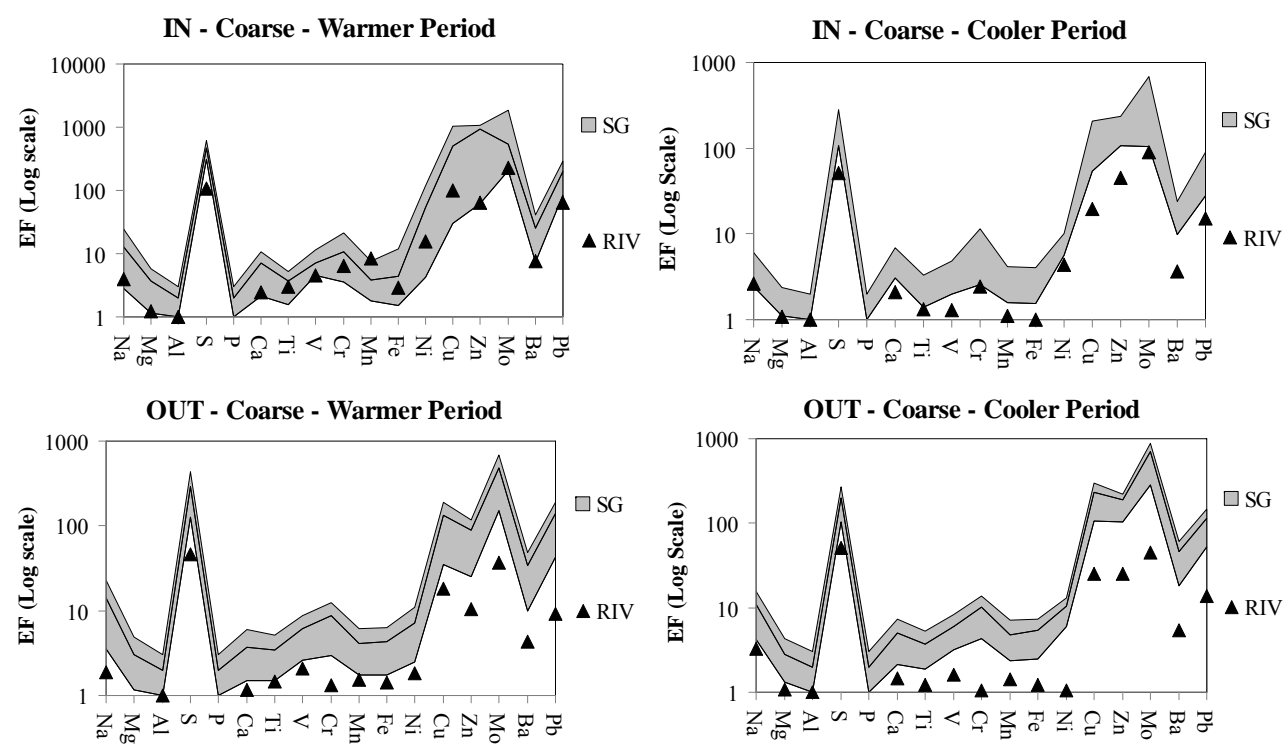

Fig. 3c. Continued.
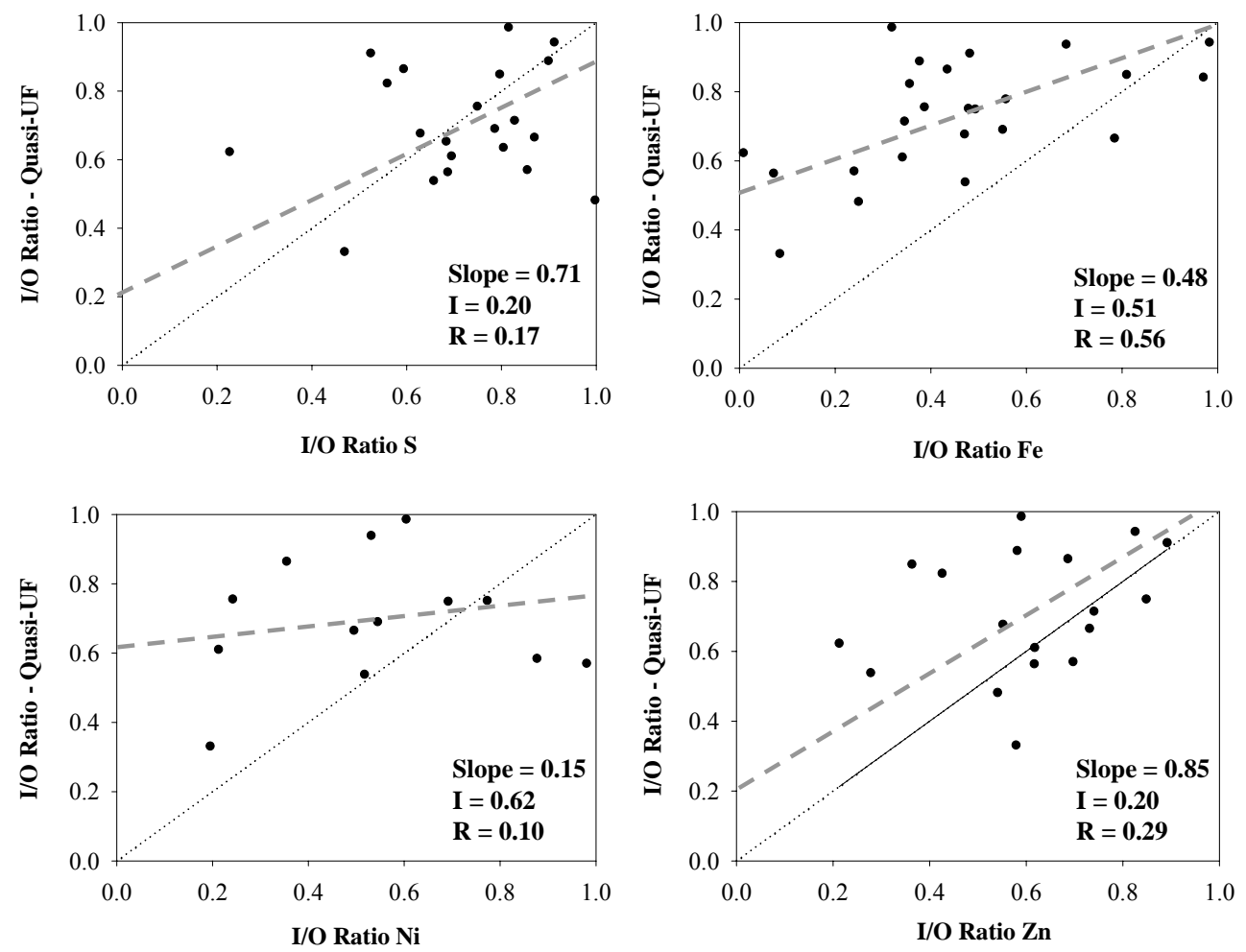

Fig. 4a. Indoor/outdoor ratios (I/O) for quasi-UF (a), accumulation (b) and coarse (c) mode PM concentrations versus the corresponding I/O ratios for $\mathrm{S}, \mathrm{Fe}, \mathrm{Ni}$, and $\mathrm{Zn}$. In each panel the 1:1 line (black dotted) is compared to the corresponding Deming regression line (grey broken). Regression slopes (S), intercept (I), and regression coefficients (R) are also included.

Figure 4a shows that none of the selected TEs was a reliable tracer for indoor quasi-UF particles of outdoor origin (regression coefficients, R, varied from 0.10 for $\mathrm{Ni}$ to 0.56 for $\mathrm{Fe}$, indicating that most data-points were widely spread around the center line). For accumulation mode particles, our analysis indicated that $\mathrm{I} / \mathrm{O}_{\text {Accumulation }}$ ratios were generally well correlated with both $\mathrm{I} / \mathrm{O}_{\mathrm{S}}$ and $\mathrm{I} / \mathrm{O}_{\mathrm{Ni}}$ ( $\mathrm{R}$ was 0.72 and 0.63 for $\mathrm{S}$ and $\mathrm{Ni}$, respectively), their regression slopes were 

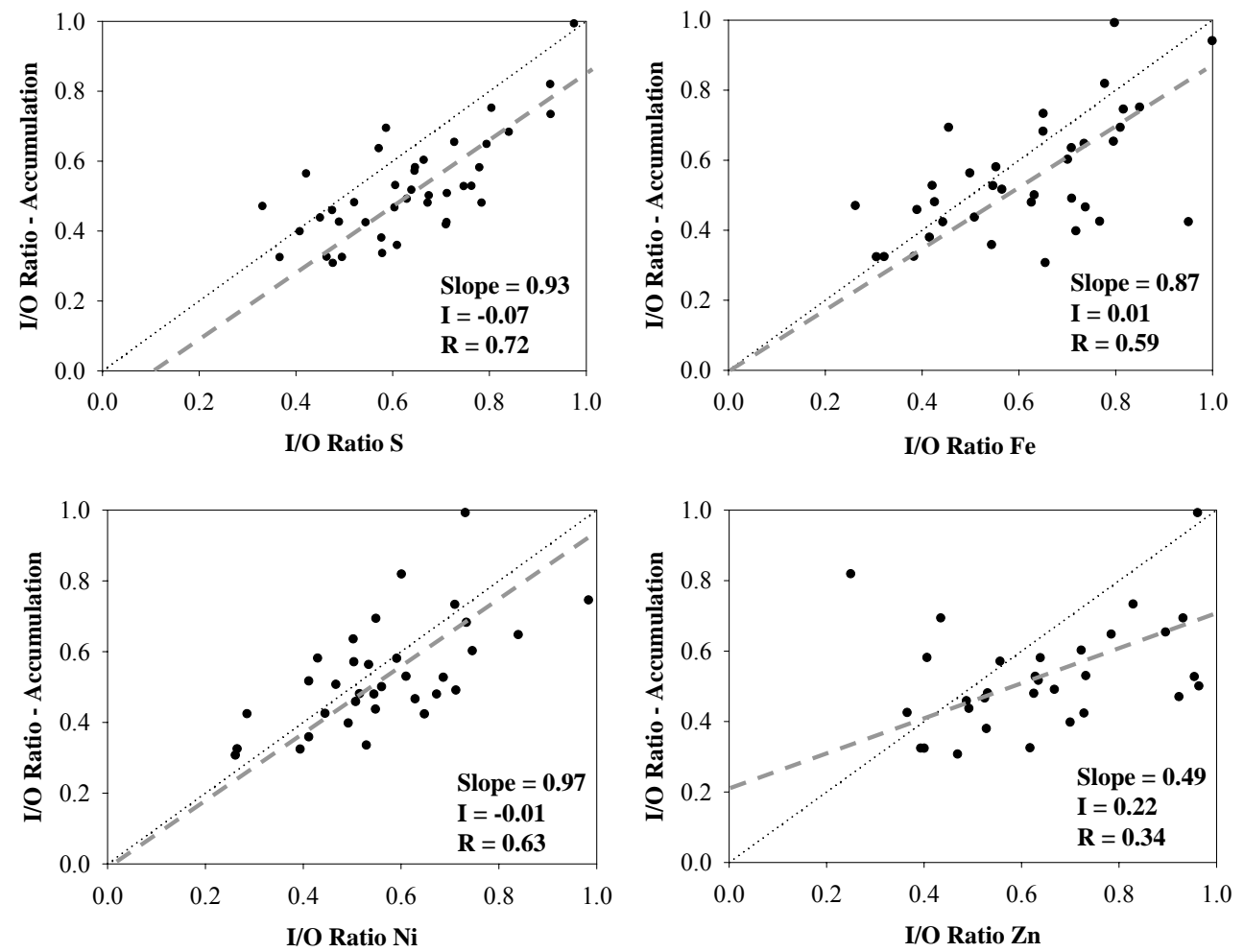

Fig. 4b. Continued.
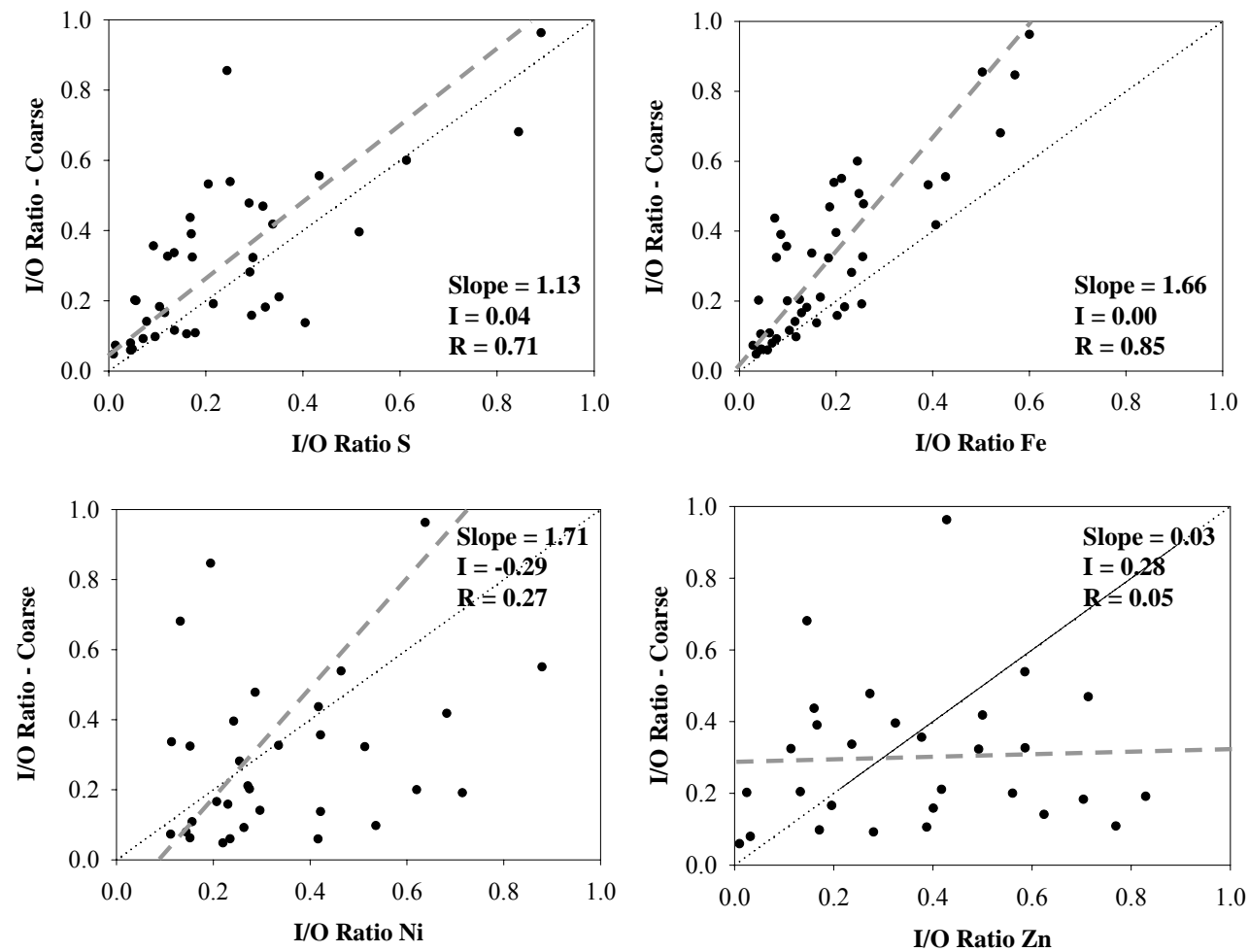

Fig. 4c. Continued. 
close to 1 ( 0.93 for $\mathrm{S}$ and 0.97 for $\mathrm{Ni}$ ), and the corresponding intercepts, I, negligible or slightly negative (values were -0.07 and -0.01 for $\mathrm{S}$ and $\mathrm{Ni}$, respectively) (Fig. $4 \mathrm{~b}$ ). These results suggest that using the $\mathrm{I} / \mathrm{O}_{\mathrm{S}}$ ratio as a surrogate of the infiltration factor for $\mathrm{PM}_{2.5}\left[\mathrm{Finf}\left(\mathrm{PM}_{2.5}\right)\right]$ might lead to an overestimation of the fraction of indoor $\mathrm{PM}_{2.5}$ of outdoor origin, at least in the communities considered in our study. Table 2 shows the average $F_{\text {inf }}$ for $\mathrm{PM}_{2.5}$ estimated during CHAPS from indoor and outdoor BAM measurements (see the "Method" section for further details). Values ranged from 0.38 to 0.52 and confirm that $\mathrm{S}$ is not a good tracer for indoorinfiltrated $\mathrm{PM}_{2.5}$ at the studied retirement homes.

This is in contrast with what was reported in previous studies conducted in the Eastern US, where $\mathrm{S}$ has been consistently assumed to be an excellent tracer of indoor infiltrated particles (Sarnat et al., 2002; Long and Sarnat, 2004; Wallace and Williams, 2005). Our differences might be due to the fact that in the Los Angeles basin (and in general in the in the Western US) a substantial portion ( 35 to $50 \%)$ of the outdoor $\mathrm{PM}_{2.5}$ mass is associated with semi-volatile labile species, most notably ammonium nitrate, but also several organics. These species volatilize either entirely or partially upon building entry (Kim et al., 2000; Tolocka et al., 2001; Lunden et al., 2003; Sardar et al., 2005). The average $F_{\text {inf }}$ for ammonium nitrate reported by Lunden et al. (2003) and Sarnat et al. (2006) during 2 previous studies conducted in Southern California homes was $\sim 0.2$. It should also be noted that sulfate particles are generally smaller than the bulk of the accumulation mode PM, penetrate indoors with higher efficiencies, and have lower deposition rates; this is also consistent with overestimated infiltration factors obtained using $\mathrm{S}$ as a tracer of indoor-infiltrated $\mathrm{PM}_{2.5}$ (Wallace and Williams, 2005). Our data indicate that the $\mathrm{I} / \mathrm{O}_{\mathrm{Ni}}$ ratio might provide more reliable estimates of $F_{\text {inf }}\left(\mathrm{PM}_{2.5}\right)$ than the correspondent $\mathrm{I} / \mathrm{O}_{\mathrm{S}}$ ratio, despite of the higher uncertainties related to the detection of relatively lower indoor and outdoor $\mathrm{Ni}$ concentrations.

As shown in Fig. 4c, the I/O ratios of $\mathrm{Ni}$ and $\mathrm{Zn}$ were not well correlated to the correspondent $\mathrm{I} / \mathrm{O}_{\text {coarse }}$ values, but relatively strong associations and negligible regression intercepts were observed between $\mathrm{I} / \mathrm{O}_{\mathrm{S}}, \mathrm{I} / \mathrm{O}_{\mathrm{Fe}}$, and $\mathrm{I} / \mathrm{O}_{\text {coarse }}$ (Slope $=1.13$ and $\mathrm{I}=0.04$ for $\mathrm{I} / \mathrm{O}_{\mathrm{S}}$ vs. $\mathrm{I} / \mathrm{O}_{\text {coarse }}$; Slope $=1.66$ and $\mathrm{I}=0.00$ for $\mathrm{I} / \mathrm{O}_{\mathrm{Fe}}$, vs $\left.\mathrm{I} / \mathrm{O}_{\text {coarse }}\right)$. However, regression slopes substantially higher than 1 for such correlations indicate that $\mathrm{I} / \mathrm{O}_{\mathrm{S}}$ and, especially, $\mathrm{I} / \mathrm{O}_{\mathrm{Fe}}$ ratios would probably lead to an underestimation of $F_{\text {inf }}$ for coarse PM, limiting the use of $\mathrm{Fe}$ as a good tracer of indoor-infiltrated coarse PM of outdoor origin. It is possible that the indoor concentrations of these TEs are dependent on structural characteristics and ventilation conditions of the considered retirement homes, and that the reduced penetration of Fe compared to coarse PM reflects the low number of open windows and doors, the presence of central air conditioners and, overall, the low AER values estimated during CHAPS (as discussed earlier).

\section{Conclusions}

Because most TEs are emitted from different anthropogenic and natural sources, their reliability as tracers of individual mobile and stationary sources in a vast area like the one considered in our study is questionable. Thus, rather than identifying specific individual TE sources, our results illustrate differences among various source categories, and suggest that during CHAPS a complex mix of vehicular-, industrial, and soil-related emissions was mainly responsible for the elemental concentrations measured at the three San Gabriel sites, while regional transport, soil re-suspension and, to a lower degree, local traffic contributed to increase the elemental levels in Riverside.

Sulfur, Ni, Zn, and Fe were not reliable tracers of indoor quasi-UF particles of outdoor origin, and using the $\mathrm{I} / \mathrm{O}_{\mathrm{S}}$ ratio as a surrogate of the infiltration factor for $\mathrm{PM}_{2.5}\left[\operatorname{Finf}\left(\mathrm{PM}_{2.5}\right)\right]$ led to an overestimation of the fraction of $\mathrm{PM}_{2.5}$ of outdoor origin measured indoors. Our differences may be due to the fact that in the Los Angeles basin (and in general in the Western US) $\mathrm{PM}_{2.5}$ includes a number of semi-volatile labile species, such as ammonium nitrate and several organic compounds, which volatilize either entirely or to a substantial degree upon building entry. Although our data indicates that the $\mathrm{I} / \mathrm{O}_{\mathrm{Ni}}$ ratio might provide more reliable estimates of $F_{\text {inf }}\left(\mathrm{PM}_{2.5}\right)$ than the correspondent $\mathrm{I} / \mathrm{O}_{\mathrm{S}}$ ratio, we speculate that it is not prudent to use a conservative compound $(\mathrm{Ni})$ to monitor the infiltration behavior a "nonconservative" species $\left(\mathrm{PM}_{2.5}\right)$. Thus, we recommend using continuous indoor and outdoor BAM measurements to calculate $F_{\text {inf }}$ for $\mathrm{PM}_{2.5}$ instead.

Unlike previous studies (Long and Sarnat, 2004; Janssen et al., 2005; Wallace and Williams, 2005), our work does not support the use of residential outdoor (and, perhaps, central site) $\mathrm{S}$ and Ni data as surrogates of indoor-infiltrated particles in time series epidemiological investigations of indoor (and personal) exposure to PMof outdoor origin. Our findings highlight the difficulty for these TEs to represent accurately the entire PM mixture due to their different infiltration behavior with respect to quasi-UF, accumulation, and coarse particles. However, a better understanding of how ambient elemental species penetrate in indoor environments is important for assessing exposure and potential health effects of these specific PM constituents.

\section{Supplemental information}

Geometric means $\left(\mathrm{ng} / \mathrm{m}^{3} \pm\right.$ standard deviation) of indoor (IN) and outdoor (OUT) weekly concentrations for the 17 most abundant elemental species detected at the 4 retirement communities during CHAPS (i.e. $\mathrm{Na}, \mathrm{Mg}, \mathrm{Al}, \mathrm{S}, \mathrm{K}$, $\mathrm{Ca}, \mathrm{Ti}, \mathrm{V}, \mathrm{Cr}, \mathrm{Mn}, \mathrm{Fe}, \mathrm{Ni}, \mathrm{Cu}, \mathrm{Zn}, \mathrm{Mo}, \mathrm{Ba}$, and $\mathrm{Pb}$ ). Data were segregated by site and by season (warmer, W, 
and the colder, C) http://www.atmos-chem-phys.net/9/4521/ 2009/acp-9-4521-2009-supplement.pdf.

Acknowledgements. We would like to give special thanks and credit to Mike Olson, Martin Shafer, Pat Gorski, Dustin Helmer and the staff at the Wisconsin State Laboratory of Hygiene for the chemical analysis of the collected samples. This project was supported by grant ES12243 from the National Institute of Environmental Health Sciences, National Institutes of Health; the California Air Resources Board contract 03-329; and US Environmental Protection Agency STAR grant RD833743. The contents are solely the responsibility of the authors and do not necessarily represent the official views of the funding agencies. The authors declare they have no competing financial interests.

Edited by: K. Hämeri

Reviewed by: T. Lanki and M. Tolocka

\section{References}

Abt, E., Suh, H. H., Catalano, P. J., and Koutrakis, P.: Relative Contribution of Outdoor and Indoor Particle Sources to Indoor Concentrations, Environ. Sci. Technol., 34, 3579-3587, 2000.

Adgate, J. L., Mongin, S. J., Pratt, G. C., Zhang, J., Field, M. P., Ramachandran, G., and Sexton, K.: Relationships between personal, indoor, and outdoor exposures to trace elements in $\mathrm{PM}_{2.5}$, Sci. Total Environ., 386, 21-32, 2007.

Arhami, M., Sillanpää, M., Hu, S., Geller, M. D., Schauer, J. J. and Sioutas, C.: Size-segregated Inorganic and Organic Components of PM In the Communities of the Long Angeles Harbor Across Southern Los Angeles Basin, California, Aerosol Sci. Tech., 43(2), 145-160, 2009.

Arhami, M., Minguillón, M. C., Polidori, A., Schauer, J. J., Delfino, R. J., and Sioutas, C.: Organic Compound Characterization and Source Apportionment of Indoor and Outdoor Quasi-ultrafine PM in Retirement Homes of the Los Angeles Basin, Submitted for publication to Indoor Air, 2008.

ATSDR (Agency for Toxic Substances and Disease Registry). Toxicological profile information sheet, http://www.atsdr.cdc.gov/ toxprofiles, 2003.

Birmili, W., Allen, A. G., Bary, F., and Harrison, R. M.: Trace metal concentrations and water solubility in size-fractionated atmospheric particles and influence of road traffic, Environ. Sci. Technol., 40, 1144-1153, 2006.

Burnett, R. T., Brook, J., Dann, T., Delocla, C., Philips, O., Cakmak, S., Vincent, R., Goldberg, M. S., and Krewski, D.: Association Between Particulate- and Gas-phase Components of Urban Air Pollution and Daily Mortality in Eight Canadian Cities, Inhalation Toxicology, 12 (suppl. 4), 15-39, 2000.

Chao, C. Y. and Wong, K. K.: Residential indoor PM10 and $\mathrm{PM}_{2.5}$ in Hong Kong and the elemental composition, Atmos. Environ., 36, 265-277, 2002.

Claiborn, C. S., Larson, T., and Sheppard, L.: Testing the metals hypothesis in Spokane, Washington, Environmental Health Perspective, 110 (suppl. 4), 547-52, 2002.

Delfino, R. J., Staimer, N., Tjoa, T., Polidori, A., Arhami, M., Gillen, D. L., Kleinman, M. T., Vaziri, N. D., Longhurst, J., Zaldivar, F., and Sioutas, C.: Circulating biomarkers of inflammation, antioxidant activity, and platelet activation are associ- ated with primary combustion aerosols in subjects with coronary artery disease, Environmental Health Perspectives, 116, 898906, 2008.

Dreher, K. L., Jaskot, R. H., Lehmann, J. R., Richards, J. H., McGee, J. K., Ghio, A. J., and Costa, D. L. Soluble transition metals mediate residual oil fly ash induced acute lung injury, J. Toxicol. Env. Health, 3, 285-305, 1997.

Geller, M. D., Chang, M., Sioutas, C., Ostro, B. D., and Lipsett, M. J.: Indoor/outdoor relationship and chemical composition of fine and coarse particles in the southern California deserts, Atmos. Environ., 36, 1099-1110, 2002.

Herner, J. D., Green, P. G., and Kleeman, M. J.: Measuring the trace elemental composition of size-resolved airborne particles, Environ. Sci. Technol., 40, 1925-1933, 2006.

Isakson, J., Persson, T. A., and Lindgren, E. S.: Identification and Assessment of Ship Emissions and their Effects in the Harbor of Gothenburg, Sweden, Atmos. Environ., 35, 3659-3666, 2001.

Janssen, N. A., Lanki, T., Hoek, G., Vallius, M., De Hartog, J. J., Van Grieken, R., Pekkanen, J., and Brunekreef, B.: Associations between ambient, personal, and indoor exposure to fine particulate matter constituents in Dutch and Finnish panels of cardiovascular patients, Occup. Environ. Med., 62, 868-877, doi:10.1136/oem.2004.016618, 2005.

Jones, N. C., Thornton, C. A., Mark, D., and Harrison, R. M.: Indoor/Outdoor Relationships of Particulate Matter in Domestic Homes with Roadside, Urban and Rural Locations, Atmos. Environ., 34, 2603-2612, 2000.

Kim, B. M., Teffera, S., and Zeldin, M. D.: Characterization of $\mathrm{PM}_{2.5}$ and $\mathrm{PM}_{10}$ in the South Coast Air Basin of Southern California: Part 1-Spatial Variations, J. Air Waste Manage., 50, 2034-2044, 2000.

Klepeis, N. E., Nelson, W. C., Ott, W. R., Robinson, J. P., Tsang, A. M., Switzer, P., Behar, J. V., Hern, S. C., and Engelmann, W. H.: The National Human Activity Pattern Survey (NHAPS): a Resource for Assessing Exposure to Environmental Pollutants, J. Expo. Anal. Env. Epid., 11, 231-252, 2001.

Koutrakis, P., Briggs, S. L. K., and Leaderer, B. P.: Source Apportionment of Indoor Aerosols in Suffolk and Onondaga Counties, New York, Environ. Sci. Technol., 26, 521-527, 1992.

Lin, C. C., Chen, S. J., Huang, K. L., Hwang, W. I., ChangChien, G. P., and Lin, W. Y.: Characteristics of metals in nano/ultrafine/fine/coarse particles collected beside a heavily trafficked road, Environ. Sci. Technol., 39(21), 8113-8122, 2005.

Long, C. M., Suh, H., Catalano, P., and Koutrakis, P.: Using Timeand Size- Resolved Particulate Data to Quantify Indoor Penetration and Deposition Behavior, Environ. Sci. Technol., 35, 20892099, 2001.

Long, C. M. and Sarnat, J. A.: Indoor-Outdoor Relationships and Infiltration Behavior of Elemental Components of Outdoor $\mathrm{PM}_{2.5}$ for Boston-Area Homes, Aerosol Sci. Tech., 38(S2), 91104, 2004.

Lunden, M. M., Revzan, K. L., Fischer, M. L., Thatcher, T. L., Littlejohn, D., Hering, S. V., and Brown, N. J.: The Transformation of Outdoor Ammonium Nitrate Aerosols in the Indoor Environment, Atmos. Environ., 37, 5633-5644, 2003.

Milford, J. B. and Davidson, C. I.: The Sizes of Particulate Trace Elements in the Atmosphere-A Review, Journal of Air Pollution Control Association, 35, 1249-1260, 1985. 
Misra, C., Singh, M., Shen, S., et al.: Development and evaluation of a personal cascade impactor sampler (PCIS), Journal of the Aerosol Science 2002, 33, 1027-104, 2002.

Nel, A.: Air pollution-related illness: effects of particles, Science, 309(5739), 1326-1326, 2005.

Ntziachristos, L., Ning, Z., Geller, M. D., Sheesley, J. J., Schauer, J. J., and Sioutas, C.: Fine, ultrafine and nanoparticle trace element compositions near a major freeway with a high heavy-duty diesel fraction, Atmos. Environ., 41, 5684-5696, 2007.

Office of Environmental Health Hazard Assessment, http://oehha. ca.gov/public_info/facts/chrom6facts.html

Polidori, A., Arhami, M., Delfino, R. J., and Sioutas, C.: IndoorOutdoor Relationships, Trends and Carbonaceous Content of Fine Particulate Matter in Retirement Homes of the Los Angeles Basin, J. Air Waste Manag. Assoc., 57, 366-379, 2007.

Pope, C. A. and Dockery, D. W.: Health effects of fine particulate air pollution: Lines that connect, J. Air Waste Manag. Assoc., 56(6), 709-742, 2006.

Saldiva, P. H. N., Clarke, R. W., Coull, B. A., Stearns, R. C., Lawrence, J., Murthy, G. G. K., Diaz, E., Koutrakis, P., Suh, H., Tsuda, A., and Godleski, J. J.: Lung inflammation induced by concentrated ambient air particles is related to particle composition, American Journal of Respiratory and Critical Care Medicine, 165(12), 1610-1617, 2002.

Sanders, P. G., Xu, N., Dalka, T. M., and Maricq, M. M.: Airborne brake wear debris: size distributions, composition, and a comparison of dynamometer and vehicle tests, Environ. Sci. Technol., 37, 4060-4069, 2003.

Sarnat, J. A., Long, C. M., Koutrakis, P., Coull, B. A., Schwartz, J., and Suh, H. H.: Using Sulfur as a Tracer of Outdoor Fine Particulate Matter, Environ. Sci. Technol., 36, 5305-5314, 2002.

Sardar, S. B., Fine, P. M., Jaques, P. A., and Sioutas, C.: Seasonal and Spatial Variability of the Size-Resolved Chemical Composition of $\mathrm{PM}_{10}$ in the Los Angeles Basin, J. Geophys. Res., 110(D7), D07S08, doi:10.1029/2004JD004627, 2005.

Sarnat, S. E., Coull, B. A., Ruiz, P. A., Koutrakis, P., and Suh, H. H.: The Influences of Ambient Particle Composition and Size on Particle Infiltration in Los Angeles, CA, Residences, J. Air Waste Manag. Assoc., 56, 186-196, 2006.
Singh, M., Misra, C., and Sioutas, C.: Field evaluation of a personal cascade impactor sampler (PCIS.), Atmos. Environ., 37, 47814793, 2003.

Sternbeck, J., Sjodin, A., and Andreasson, K.: Metal emissions from road traffic and the influence of resuspension-results from two tunnel studies, Atmos. Environ., 36, 4735-4744, 2002.

Stone, E. A., Snyder, D. C., Sheesley, R. J., Sullivan, A. P., Weber, R. J., and Schauer, J. J.: Source apportionment of fine organic aerosol in Mexico City during the MILAGRO experiment 2006, Atmos. Chem. Phys., 8, 1249-1259, 2008, http://www.atmos-chem-phys.net/8/1249/2008/.

Thurston, G. D., Ito, K., Mar, T., Christensen, W. F., Eatough, D. J., and Henry, R. C.: Workgroup report: workshop on source apportionment of particulate matter health effects - intercomparison of results and implications, Environ. Health Perspect., 113(12), 1768-74, 2005.

Tolocka, M. P., Solomon, P. A., Mitchell, W., Norris, G. A., Gemmill, D. B., Wiener, R. W., Vanderpool, R. W., Homolya, J. B., and Rice, J.: East Versus West in the US: Chemical Characteristics of PM2.5 during the Winter of 1999, Aerosol Sci. Tech., 34, 88-96, 2001.

United States Environmental Protection Agency (USEPA), Air Quality Criteria for Particulate Matter, Office of Research and Development, Washington, DC, 2004.

Wallace, L. A. and Williams, R.: Use of personal-indoor-outdoor sulfur concentrations to estimate the infiltration factor, outdoor exposure factor, penetration coefficient, and deposition rate for individual homes, Environ. Sci. Technol., 39, 1707-1714, 2005.

Wang, X., Bi, X., Sheng, G., and Fu, J.: Hospital indoor $\mathrm{PM}_{10} / \mathrm{PM}_{2.5}$ and associated trace elements in Guangzhou, China, Sci. Total Environ., 366, 124-135, 2006.

Weschler, C. J. and Shields, H. C.: Potential reactions among indoor pollutants, Atmos. Environ., 31, 3487-3495, 1997.

Weschler, C. J.: Chemical reactions among indoor pollutants: What we've learned in the new millennium, Indoor Air, Supplement, 7, 184-194, 2004. 